\title{
The dynamic evolution of compaction bands in highly porous carbonates: the role of local heterogeneity for nucleation and propagation
}

\author{
Xiao Chen ${ }^{1}$, Hamid Roshan ${ }^{1}$, Adelina Lv', Manman Hu${ }^{2,1}$ and Klaus Regenauer-Lieb ${ }^{1 *}$ (1)
}

\begin{abstract}
The formation of compaction bands in porous brittle rocks such as sandstones and carbonates has a significant impact on the localization mechanisms preceding earth and planetary surface instabilities such as earthquakes, landslides, and plate boundary faults. The micromechanics underpinning the dynamics of the formation of compaction bands and its effect on alteration of pore fluid pathways are not yet fully understood. The current study seeks to understand the mechanical properties of compaction in highly porous carbonate at micro- and macro-scale using time-lapse triaxial experiments in an X-ray transparent flow and deformation cell. Images were obtained with increasing axial strain levels using $X$-ray computed tomography allowing mapping of the evolution of internal structures. In addition to the $X$-ray analysis, digital image correlation (DIC) was used to quantify the evolution of strain and precisely identify the nucleation mechanism of compaction bands and its dynamics. The effect of friction on the boundary platens was shown to be minimal as evidenced by shear strain obtained from DIC analysis. This comprehensive analysis allowed assessment of the role of heterogeneity for the initiation of compaction bands. Local regions with high porosity provide the initial seeds for discrete compaction followed by the nucleation of traveling waves that lead to diffuse growth of the compaction zone. This interesting phenomenon is expected to be a fundamental mode of compressional deformation in porous brittle media where discrete, often periodic, deformation bands are observed on compaction.
\end{abstract}

Keywords: Compaction bands, Image processing, Digital image correlation, Time series analysis, Microstructure

\section{Introduction}

Compaction bands are defined as tabular zones of purely localized compressive deformation that are developed perpendicular to the direction of maximum compressive principal stress (Issen and Rudnicki 2001; Eichhubl et al. 2010; Wong and Baud 2012). Compaction bands play a critical role in controlling fluid flow. Compaction bands can have a contrasting

\footnotetext{
*Correspondence: klaus@unsw.edu.au

'School of Mineral and Energy Resources Engineering, UNSW Sydney, Kensington, Sydney, NSW, Australia

Full list of author information is available at the end of the article
}

impact on fluid flow depending on their geometry (Baud et al. 2012). The majority of studies emphasize the local decrease in porosity and consider compaction bands as flow barriers for fluid flow in reservoirs (Vajdova et al. 2004; Sternlof et al. 2006; Deng et al. 2015). Detrimental effects of the compaction bands have also been reported in the wellbore region during injection or extraction of fluid for storage or hydrocarbon production (Haimson 2001; Haimson and Kovacich 2003; Rahmati et al. 2014). Some authors also attribute this phenomenon to the mechanism of sand production in hydrocarbon reservoirs ( $\mathrm{Li}$ et al. 
2006; Detournay 2009). It is therefore important to understand the role of heterogeneity for the nucleation of compaction bands which is still controversially discussed (Fortin et al. 2006; Cilona et al. 2014; Baud et al. 2015). In this contribution, we present a time-lapse micro-CT experiment of compaction of a limestone (Mt Gambier limestone) of high porosity of $\sim 50 \%$ to investigate this problem using digital imaging technology.

Time-lapse Micro-CT imaging of triaxial experiments provides new insights into the $4 \mathrm{D}$-evolution of compaction bands in porous media including their effect on permeability. A recent study by Huang et al. (2019) used this technique to document the evolution of compaction bands in porous limestone (Leitha limestone) featuring an initial porosity of $22.5 \%$ and a macropore size of $165 \mu \mathrm{m}$. The study clearly showed the effect of the strong heterogeneity of local porosity near the top of the sample on the formation of distributed and localized compaction. A first region of collapsing highest porosity clusters in the top part of the sample was observed followed by the second stage of collapse of clusters of macropores in the lower part. The interesting role of local heterogeneity on the dynamics of pore collapse also has strong implications on the permeability evolution of the sample.

Compaction bands were first reported through field observation in Jurassic Aztec sandstone of south-eastern Nevada by Hill (1993) and later studied by others (Sternlof et al. 2005; Eichhubl et al. 2010; Sun et al. 2011). Compaction bands have been also observed in naturally deformed carbonates (Tondi et al. 2006; Rustichelli et al. 2012).

Understanding the control of compaction bands on fluid flow and possible sand production is crucial for oil and gas production, and therefore, numerous triaxial experiments have been conducted in the past supported by thin section analyses post deformation. These laboratory triaxial experiments, mimicking geological stress conditions, have been performed using different rocks, e.g., sandstone (Baud et al. 2004; Fortin et al. 2005; Townend et al. 2008; Charalampidou et al. 2011), carbonates (Ji et al. 2012; Baud et al. 2017), soil (Arroyo et al. 2005), clay (Hashimoto et al. 2019), and mudstone (Oka et al. 2011). Interestingly, compaction bands have been observed in applications outside of geoscience areas such as foam (Bastawros et al. 2000), honeycomb (Papka and Kyriakides 1998), snow (Barraclough et al. 2016), and puffed rice (Guillard et al. 2015).

The controlled laboratory experiments have shown that the porosity and permeability of the compaction bands can be significantly reduced by internal pore structure changes inside the band with potential pore collapse (Holcomb and Olsson 2003; Baxevanis et al.
2006; Lenoir et al. 2010; Chen et al. 2017). The accompanied permeability reduction can be empirically linked to axial strain recorded during the formation of compaction bands in laboratory experiments (Vajdova et al. 2004; Fortin et al. 2005). Tembe et al. (2008) noted that the thickness and length of compaction bands obey a quadratic scaling relation. In a similar study, Townend (2008) showed that the compaction bands nucleate at the edge and propagate across the specimen at 0.08 $\mathrm{mm} / \mathrm{s}$ by collecting acoustic emission responses for Diemelstaedt sandstone samples. In other experiments, localized compaction bands were triggered in a predetermined location of the specimen by carving a geometric imperfection (e.g., V-shaped circumferential notch) around the middle of the sample (Vajdova and Wong 2003; Tembe et al. 2006; Charalampidou et al. 2011; Charalampidou et al. 2014). Baud et al. (2004) and Fortin et al. (2006) identified three different patterns of bands in triaxial testing including discrete compaction bands, diffuse compaction bands, and high-angle shear bands. More recently, McBeck et al. $(2018,2020)$ reported that the proximity to macroscopic failure can be predicted using local strain information from dynamic in situ X-ray tomography. The proposed technique is to combine triaxial compression experiments on different rock types with the machine learning analyses. The results suggested that similar strain accumulation processes may precede macroscopic failure. However, the technique did not allow direct measurement of changes in the local stress fields of the samples.

Pioneering works with the aim of measuring the local stress variations were conducted to investigate the fracturing and crushing of grains and their effect on the macroscopic behavior of granular media (Hurley et al. 2018). The method relied on the use of analog granular materials (e.g., sapphire) with known mechanical properties so that the local stress field can be inverted from the X-ray CT images. Unfortunately, this technique does not lend itself to our experiments with highly porous limestones. The local material properties are unknown as it is a heterogeneous material that has complex microstructures, microfossils, and morphology. Our method is therefore similar to existing techniques for assessing meso-scale localized strain fields down to the strain of individual grains. This is accessible using X-ray tomography and DIC analysis at the grain scale (Hall et al. 2012; Takano et al. 2015).

In the past decades, the majority of studies of compaction bands were conducted on sandstone. Cheung et al. (2012) concluded that a homogeneous grain size distribution is the main microstructural attribute promoting the development of compaction bands in sandstone. However, compaction localization has not 
been investigated to the same level in a more complex microstructure such as a carbonate (e.g., mineralogy, deposition, and diagenesis) (Rashid et al. 2017). New findings may be expected for a highly porous and extremely heterogeneous carbonate rock with a dual-porosity profile like Mount Gambier limestone as chosen in this study. Due to the macro-pore heterogeneity caused by fossil shells and micro-pore heterogeneity from bryozoae (Fig. 1a), the limestone provides an ideal testbed to investigate the heterogeneity problem. Previous studies suggested that rock heterogeneity may enhance compaction localization (Han et al. 2013; Cilona et al. 2014). Nucleation of compaction bands may, however, also be affected by experimental stress boundary conditions (such as boundary friction) (Fortin et al. 2006). Due to the lack of dynamic imaging, the causal relationship between the collapse of the high porosity clusters and nucleation of the compaction bands is still debated (Baud et al. 2015). In this study, we provide direct imaging insights and investigate whether the aforementioned studies can be generalized.

We have therefore conducted two sets of triaxial experiments on carbonate with similar rock composition. The main difference between the two samples was the location of the high porosity and low porosity

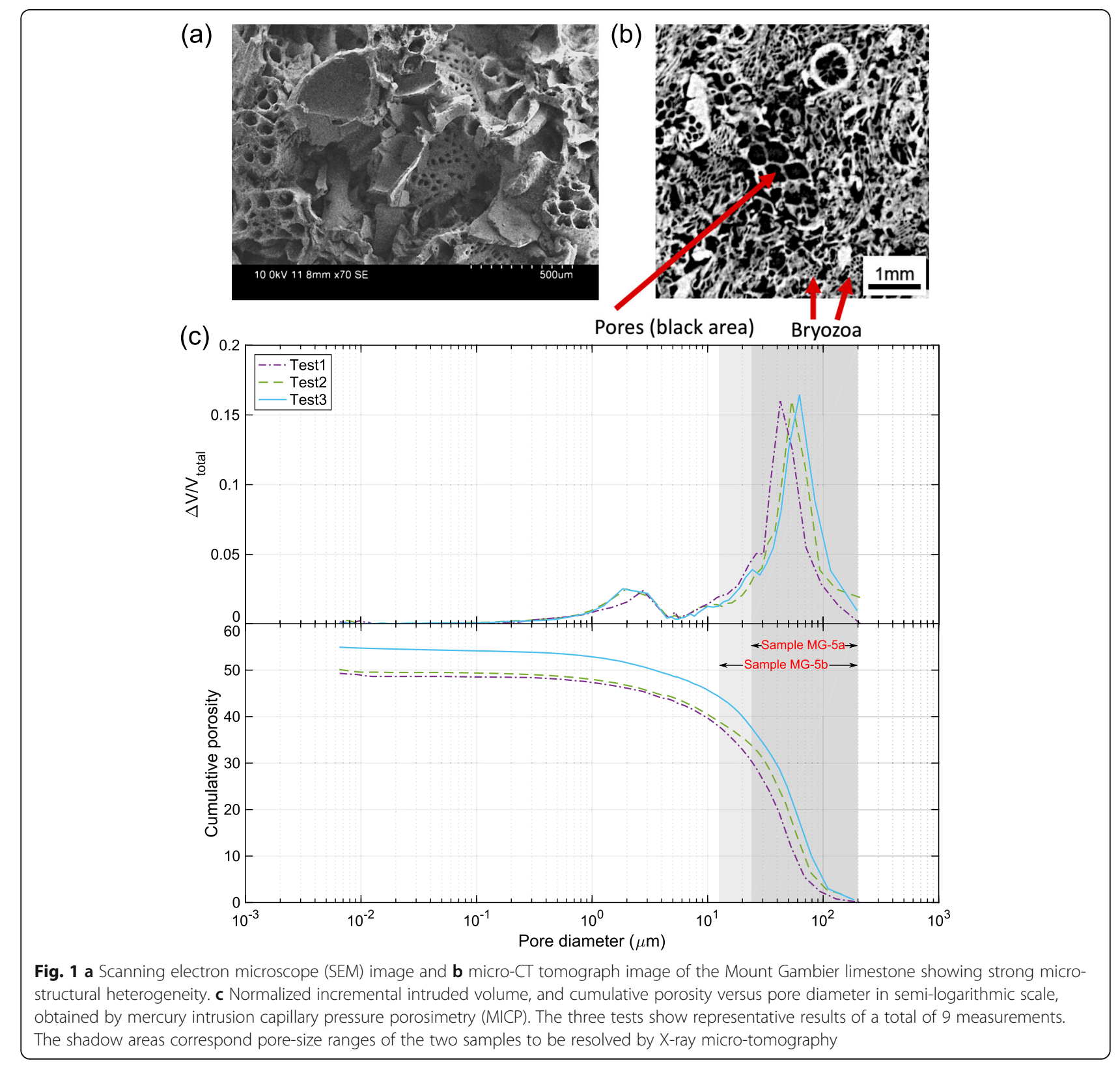


regions. The first sample features the highest porosity slightly below the center of the sample, and the second features two areas of high porosity exactly in the middle of the sample and slightly above the center. Both samples have dual-porosity profiles with macropores ranging from 10 to 200 microns and nanomicropores ranging from 0.1 to 5 microns. The particular focus of this study is to use digital rock techniques to relate the initial heterogeneity of the sample to the compaction band evolution and record the microstructural changes during the formation of compaction bands.

The samples were imaged using micro-CT at several stages of deformation. The results have been analyzed by digital image correlation (DIC) technique to map the 2 crosssections at right angles of the axially symmetric strain field.

\section{Methods/Experimental Sample preparation}

The carbonate samples used in this study are from the Gambier Embayment of Otway, the basin of Paleogene-Neogene age in southern South Australia (Bourman et al. 2016). Mount Gambier limestone is a highly porous, fossiliferous carbonate which is originated from extensive colonies of Bryozoa (or lace coral) that flourished on an open-marine shelf, formed over 30 million years ago. Its composition consists of Bryozoa, Foraminifera, and Echinoid spines and plates (Love et al. 1993). X-ray diffraction (XRD) analyses showed that the sample essentially consists of calcite (96\%) with a small contribution of quartz, magnesite, and magnetite (accounting for the remaining 4\%). An X-ray CT tomograph image of the studied carbonate is shown in Fig. 1b. The image shows material microstructure mainly consisting of carbonate bioclasts and shell fragments. Following the standard triaxial testing protocol (ISRM 2007), specimens were cored with a 2:1 length-diameter ratio from a single carbonate block with approximately $12.7 \mathrm{~mm}$ in diameter and $25.4 \mathrm{~mm}$ in length. In order to reduce the effect of moisture, all samples were placed in a vacuum oven at $110{ }^{\circ} \mathrm{C}$ for $48 \mathrm{~h}$ and the temperature was then reduced to room temperature for another $24 \mathrm{~h}$ prior to experiments. All experiments were conducted at room temperature.

In order to collect information on the pore size distribution of the sample, mercury injection experiments were conducted using a micrometrics POREMASTER PM-33 (Roshan et al. 2016) (Fig. 1c). The mercury intrusion capillary pressure measurement (MICP) employs a pressurized chamber to force mercury into the porous materials, where the volume of that mercury enters the pores is related to pore volume. Based on the assumption of cylindrical pores, the pore size distribution can be described according to Washburn (1921) by:

$$
P=\frac{-4 \gamma \cos \theta}{d}
$$

where $P$ is measured pressure, $\gamma$ is the surface tension of mercury, $\theta$ is the contact angle of mercury, and $d$ is the pore diameter when mercury enters at pressure $P$. In this study, the mercury surface tension and the contact angle value of $48 \mathrm{~N} / \mathrm{m}^{2}$ and $140^{\circ}$ were used, respectively (Adamson and Gast 1967). Nine samples were investigated by mercury intrusion experiments (three representative measurements are shown in Fig. 1c) leading to an average interconnected porosity of $51.5 \%$. In order to gain confidence in the porosity measurement by MICP, independent porosity was measured on three core samples using helium porosimetry (TPI-219 Helium Porosimeter) and an average total porosity of $53.1 \%$ was obtained, i.e., as the sample is highly porous, the effective and total porosity are assumed identical.

Figure 1a, b shows that the Mount Gambier limestone has a geometrically complex percolative backbone through the macropores $(10-200 \mu \mathrm{m})$ supported by a solid matrix with a population of micro-pores sizes ranging from 0.1 to $5 \mu \mathrm{m}$. Similar results have been reported by Shahin et al. (2019) using Tuffeau de Maastricht limestone ( $53 \%$ porosity) and Ji et al. (2014) using Majella limestone (30\% porosity). Two distinct pore throat clusters are evident from Fig. 1c, i.e., incremental intrusion volume divided by the overall intrusion volume showing the pore size distribution. The area under the curves represents the normalized volume of the pores (total normalized volume is equal to 1). MICP measurements indicate that a small volume fraction of smaller clusters, here called micro-pores $(<5 \mu \mathrm{m})$, cannot be resolved by micro-CT. This comprises around $10 \%$ of the overall porosity.

\section{Experimental set-up}

Before running the experiments, a series of triaxial experiments on larger samples were conducted on the specimens at different confining pressure ranging from 1 to $5 \mathrm{MPa}$ (see Appendix, Fig. A1). A confining pressure of $5 \mathrm{MPa}$ was found to trigger pure compaction bands in Mount Gambier Limestone.

In our study, a new X-ray transparent triaxial cell was used (Roshan et al. 2019a) to conduct time-lapse X-ray CT imaging (schematic diagram shown in Fig. 2). The body of the cell was made of PEEK (polyether ether ketone), an X-ray transparent material with enough strength and stiffness to hold required confining pressures. The overall design is similar to a previously 


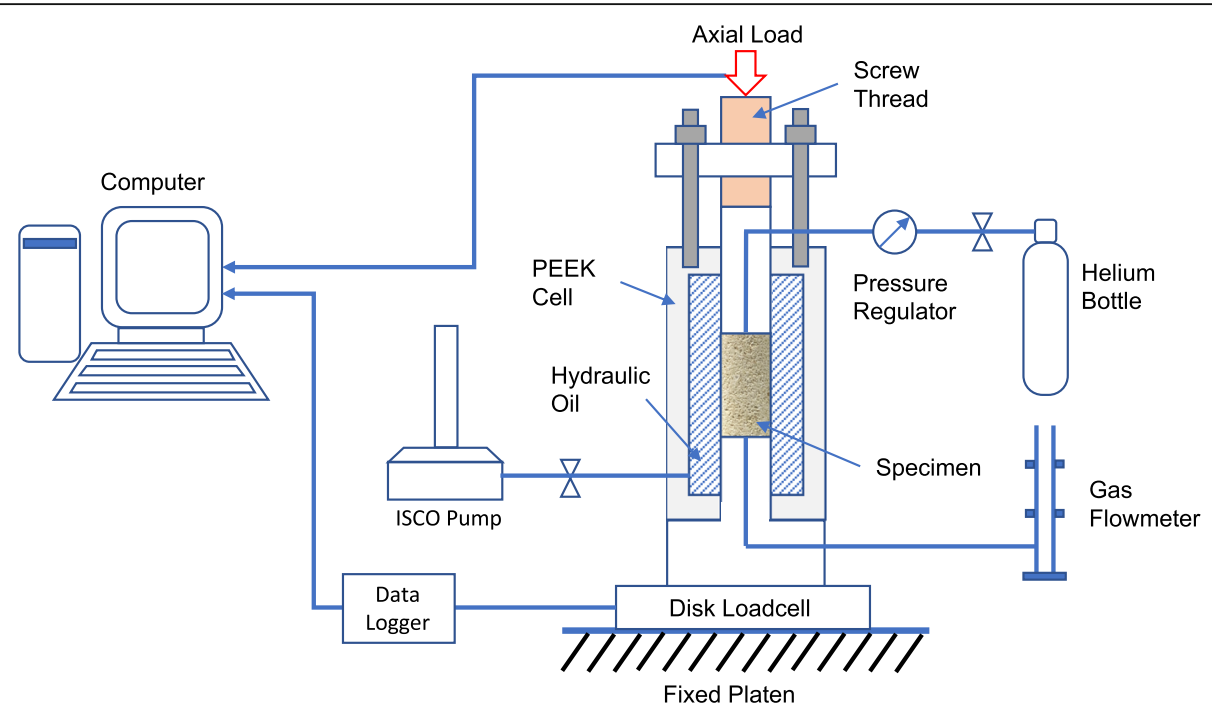

Fig. 2 Schematic representation of the experimental setup for triaxial compression test for dynamic X-ray micro-CT imaging

designed larger scale triaxial cell (Roshan et al. 2019b) used for the macro-scale experiments. Carbonate specimens with 0.5 -inch $(12.7 \mathrm{~mm})$ diameter and 1-inch $(25.4 \mathrm{~mm})$ length were cored and placed in the microCT cell.

Axial loads were applied using a 100-ton servocontrolled loading frame with a displacements rate of $3 \times 10^{-3} \mathrm{~mm} / \mathrm{s}$ (corresponding to a nominal strain rate $1.18 \times 10^{-4} / \mathrm{s}$ ) at room temperature. The schematics of the experimental setup are presented in Fig. 2. The confining pressure is supplied by hydraulic oil with a Teledyne ISCO Pump (500D) with control up to $\pm 0.007 \mathrm{MPa}$. The axial load was logged externally by the servo-controlled loading frame system with $\pm 0.05 \mathrm{kN}$ accuracy. An external Compression Disk Load cell (LPX-1000, maximum capacity of 1000 $\mathrm{kg}$ ) was placed underneath the X-ray Triaxial Cell to register a higher sampling rate of the axial load of sample MG-5b. The load cell was connected to a data logger providing also higher accuracy $( \pm 0.001 \mathrm{kN})$ readings of the axial load compared to the accuracy $( \pm 0.05 \mathrm{kN})$ registration of the loading frame. The axial strain was measured with reference to the piston movement of the loading frame. The radial strain and volumetric strain were calculated from the obtained $3 \mathrm{D}$ tomography images. Axial and radial displacements have an accuracy of $\pm 0.001 \mathrm{~mm}$ and \pm 0.02 $\mathrm{mm}$, respectively. All the experiments and scans were conducted at room temperature $\left(\sim 25{ }^{\circ} \mathrm{C}\right)$.

In this work, compressive stress and strain are considered positive and tensile stress and strain negative. The volumetric strain is described as $\varepsilon_{v}=\varepsilon_{a}+2 \varepsilon_{r}$ where $\varepsilon_{a}$ is axial strain and $\varepsilon_{r}$ is radial strain. The differential stress is defined by $q=\sigma_{1}-\sigma_{3}$ and the effective mean stress is defined as $p=\left(\sigma_{1}+\sigma_{2}+\sigma_{3}\right) / 3-p_{p}$, where $\sigma_{1}$ is axial compression (maximum) stress, $\sigma_{3}=\sigma_{2}$ is the confining pressure (minimum) and $p_{p}$ is pore pressure.

Stress-strain analysis and failure patterns offer a macroscopic understanding of overall deformation in carbonate samples. However, the microscopic processes leading to macroscopic observations of localization also need to be investigated. Therefore, 3D X-ray computed tomography and 2D digital image correlation were used to study the development and evolution of compaction bands from micro-to-macro scale (Ji et al. 2014; Lv et al. 2019).

The specimens were initially scanned in a micro-CT facility (before compression test) and then loaded isotropically to $5 \mathrm{MPa}$ stress while acquiring new series of tomographic images. Triaxial loading was then initiated and at several axial strain levels, the sample was scanned. We conducted two sets of experiments: In the first set of experiments, the sample (MG-5a) was scanned at $0 \%, 1 \%, 3 \%, 6 \%, 9 \%, 13 \%$, and $17 \%$ of axial strain. Each scan took $1 \mathrm{~h}$ to have sufficient time for tomographic imaging where the compression of the sample was kept during $1 \mathrm{~h}$ scans under static load. A resolution of $23.8 \mu \mathrm{m} /$ voxel was obtained. In order to verify the repeatability of our first experiment, a second set of experiments, the sample (MG$5 b)$ was conducted at the same experimental condition but the sample was scanned at $0 \%, 1 \%, 3.5 \%, 6 \%$, and $10 \%$ of axial strain; each scan took $2 \mathrm{~h}$, the resolution of $12.5 \mu \mathrm{m} /$ voxel was achieved. Figure 1c 
indicates the resolvable pore size (shadow area). Possible creep during the $1-2 \mathrm{~h}$ pauses was analyzed using the reconstruction code of the X-ray CT tomography images, which allows a maximum of 5 voxel deformation corresponding to an axial displacement of $100 \mu \mathrm{m}$. Within these uncertainty limits, no creep deformation was recorded.

\section{$\mathrm{X}$-ray computed tomography and image analysis}

$\mathrm{X}$-ray computed tomography is a non-destructive scanning technique which can map the internal structure of the rock sample with high resolution (Viggiani et al. 2004; Ji et al. 2012; Baud et al. 2015; Pirzada et al. 2018; Viggiani and Tengattini 2019). The technique has been used to get insights into material instabilities (Sheppard et al. 2014) such as observation of the parallel compaction bands in carbonate (Baxevanis et al. 2006; Arzilli et al. 2016) or to obtain localized 3D strain maps (Lenoir et al. 2007; Tudisco et al. 2015; Papazoglou et al. 2017; McBeck et al. 2018; Renard et al. 2019).

In our experiments, all images were acquired at the Tyree X-ray CT facility at the University of New South Wales, Sydney, Australia. The Tyree X-ray CT facility uses a HeliScan micro-CT scanner which was designed to allow easy access and ability to integrate complex flow experiments within the imaging system. The equipment has a GE Phoenix NanoFocus X-ray Tube and highquality flatbed detector. In our study, X-ray energy and tube current were set to $100 \mathrm{kV}$ and $120 \mu \mathrm{A}$, respectively. A double helix trajectory was used for all the scans. We used $0.5 \mathrm{~mm}$ stainless steel sample filter notes, and the exposure time was $0.6 \mathrm{~s}$. The resolution difference between sample MG-5a ( $23.8 \mu \mathrm{m} /$ voxel, $1 \mathrm{~h}$ scan $)$ and sample MG- $5 \mathrm{~b} \quad(12.5 \mu \mathrm{m} /$ voxel, $2 \mathrm{~h}$ scan $)$ is because for sample MG-5a, a camera binning mode was used to reduce the scanning time. The $\mathrm{X}$-ray $\mathrm{CT}$ images were reconstructed from raw cone-beam X-ray projection data obtained from helix trajectories based on Katsevich inversion formulation (Varslot et al. 2010; Kingston et al. 2016). The workflow of the image analysis includes the following steps: (a) intensity calibration, (b) noise reduction, (c) 3D image registration, (d) segmentation, and (e) 2D digital image correlation.

\section{Intensity calibration}

The equilibration of the grayscale intensity was conducted across all images acquired from each sample to obtain higher accurate registration and thresholding segmentation. Because of the effect of filament lifetime, each scan may have a slight X-ray flux difference (less than 100 intensity in our study). In order to calibrate the grayscale intensity, the grayscale of selected regions (large pores, shell fragments, cell body, rubber sleeve, and air) of images of all samples was correlated with each other, and then, differences were corrected for images of each sample using the obtained linear correlation.

\section{Noise reduction}

Prior to registration and segmentation, a nonlinear anisotropic diffusion filter (Sheppard et al. 2004) was used for edge-preserving image denoising, using a method similar to that of Frangakis and Hegerl (2001). A key parameter of the anisotropic diffusion filter is the contrast which was set as the intensity difference between the solid phase and pore phase.

\section{$3 D$ image registration}

The tomography images required registration, because the distance between X-ray source and the X-ray CT transparent cell can be affected by small variations between each scan. The obtained images were first cropped to a cylindrical shape and then registered using a 3D image registration technique developed by Latham et al. (2008). The technique brings two or more images into geometric alignment for further digital image correlation (DIC) and porosity profile analysis. In our study, each scan was registered to the previous scan, once all the images are geometrically aligned. The information from all sources can be correlated to resolve ambiguities which cannot be resolved through the examination of the individual images alone.

\section{Segmentation}

Image segmentation is the process of converting a multiphase dataset into two or more phases. In our study, the converging active contours (CAC) method was used for image segmentation (Sheppard et al. 2004; Sheppard et al. 2014). This method uses a combination of the watershed and active contour methods for the segmentation of the grayscale data. The watershed algorithm is figuratively a divide between two adjacent drainage patterns. It is used in image processing to identify changes in grayscale to a thresholding process for segmentation. The active contour method assists in this segmentation process as it allows to identify object outlines from noisy images. The two threshold values for the solid phase and pore phase were chosen based on a layer-by-layer inspection of the 3D tomogram images. In detail, once the segmentation with the initial guesses is conducted, the overall segmented images were compared to that of the original radiographs by the user. This process required a trial and error procedure where convergence was accepted, e.g., when the segmented pores were visually aligned with the original image at one-pixel resolution identified by the user. The true boundary between the solid phase and pore phase in three dimensions then converges by a function which depends on the gradient, intensity, interfacial curvature, and the geodesic distance. 


\section{$2 D$ digital image correlation}

Digital image correlation (DIC) is a modern tool which enables the full-field measurement of displacement and strain fields to obtain detailed information of shear and compaction deformations in geomaterials (Viggiani and Hall 2008; Hall et al. 2010). To investigate the localization and propagation of compaction bands, we used an open-source 2D DIC software package: Ncorr (Blaber et al. 2015), which is implemented in MATLAB. DIC uses image registration algorithms to track relative displacement of material points between a reference image and a deformed image. Ncorr uses a nonlinear correlation optimizer for image alignment. The image alignment algorithm consists of an inversion of the image difference between an identified template to assess the movement and deformation of the template. The template can be either the original undeformed image, or it can be the previous deformation step; thus, total or incremental changes can be detected from the X-ray tomographic slices. The compressive strain $\varepsilon_{y y}$ and shear strains $\varepsilon_{x y}$ were extracted from micro-CT images using the Green-Lagrangian strain tensor in an incremental form. Both $\varepsilon_{y y}$ and $\varepsilon_{x y}$ are obtained by four displacement gradients.

\section{Results}

Characteristics of stress-strain response

Figure 3 summarizes the results of axial stress versus axial strain at $5 \mathrm{MPa}$ confining pressure of two samples. Experiments with a similar high porosity (52\%) carbonate, Tuffeau de Maastricht calcarenite, (Baxevanis et al. 2006; Shahin et al. 2019) reported that at $4 \mathrm{MPa}$ confining pressure, a transition from shear bands to compaction bands occurs. At lower confining pressure $(<4 \mathrm{MPa})$, the specimens developed high-angle shear bands while above $4 \mathrm{MPa}$ confining pressure, compaction bands are formed. This transition of failure mode has been also reported in previous studies (Wong et al. 2001; Bedford et al. 2018; Bouissou et al. 2019).

In Fig. 3, arrows indicate the points when the axial load was held constant, and the specimens were scanned. The results of 2D digital image analysis were also shown in this figure, but they will be discussed later in detail. The stress-

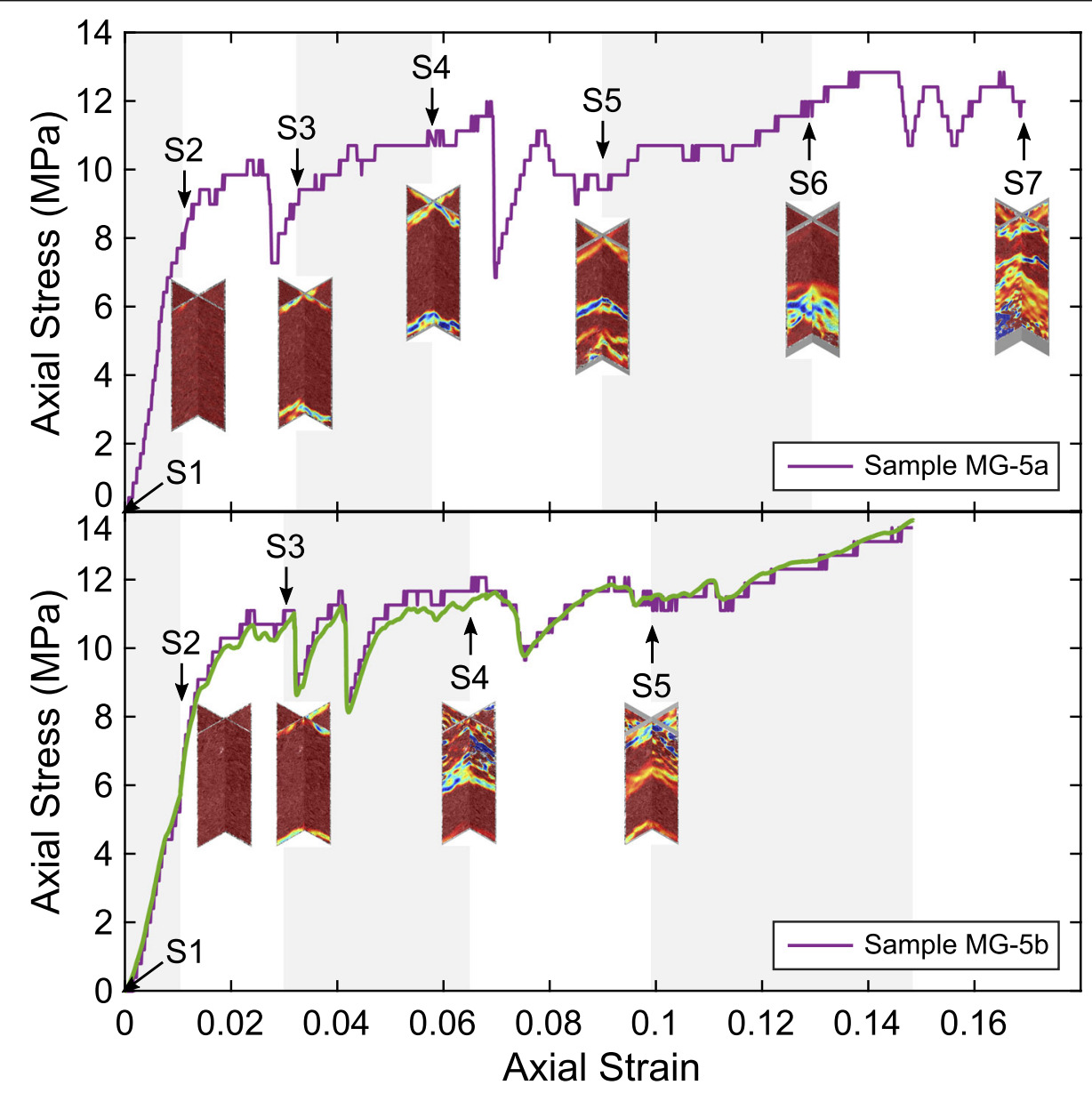

Fig. 3 Axial stress versus axial strain at 5 MPa confining pressure and 2D digital image correlation analysis results of a sample MG-5a and $\mathbf{b}$ sample MG-5b (the green color curve of sample MG-5b is the axial strain which was recorded by an externally high-resolution disk load cell). A detailed description of the incremental compressive strain shown in the DIC images will be further discussed in this section 
strain curves after yielding showed relatively large and periodic stress drops which are similar to those reported for low strength and porous rocks (Han et al. 2013; Shahin et al. 2019). Such large stress drops are not usually observed in rocks with relatively lower porosity e.g., low porosity carbonate rock (Nicolas et al. 2016) and sandstones (Chen et al. 2017). The results showed that the absolute radial strain is much lower than the axial strain (Fig. 4) showing that inelastic compaction occurred with almost no radial strain (Baud et al. 2017). This is because the highly porous structure of the sample is prone to collapse along the axial direction rather than the radial direction. A significant radial expansion can be seen at $17 \%$ axial strain (sample MG-5a).

\section{Microstructure observation}

In order to acquire a detailed map of the internal structure, the microstructural analysis was performed on two specimens using full-length X-ray computed tomography. Digital image correlation analysis was performed on both triaxial tests with $5 \mathrm{MPa}$ confining pressure to track the initiation and evolution of localized compaction bands during the experiments. Sample MG-5a was scanned seven times at 0\%, $1 \%$, 3\%, $6 \%$, 9\%, 13\%, and $17 \%$ axial strain, respectively, and sample MG-5b was scanned five times at $0 \%, 1 \%, 3 \%, 6.5 \%$, and $10 \%$ axial strain, respectively.

The aforementioned intensity calibration was performed in a sequential manner for each subsequent test in order to be able to correlate the results for all scans. A linear relationship ( $R^{2}$ ranging from 0.9994 to 0.9998 ) shows the perfect consistency of our intensity of each scan (Fig. A2 in the Appendix). Furthermore, 3D image registration was conducted based on the calibrated Xray $\mathrm{CT}$ images. The registration process aligns all the scans at one voxel accuracy such that the images overlay with maximum similarity (Latham et al. 2008).

The segmentation process of carbonate rocks presents difficulties due to a large amount of submicron pores (Gray et al. 2016). The segmentation process and results can be subjective because of over-segmentation of pores or grains. From our MICP results, there are some micropores that cannot be segmented because of the limitation of the X-ray CT resolution. Those pores account for $15 \%$ porosity of sample MG-5a and $10 \%$ porosity of sample MG-5b. This does not negatively affect our analysis as we are not focused on obtaining accurate absolute porosity values but on the evolution of the porosity during the formation of compaction bands. The overall porosity can be estimated from Xray microtomography (Renard et al. 2009), and the porosity profile can be calculated as the porosity of each layer (1 voxel thickness) along the sample from top to bottom. Figure A3 (in the Appendix) shows the porosity profile of undeformed sample MG-5b when choosing three different intensities ranges.

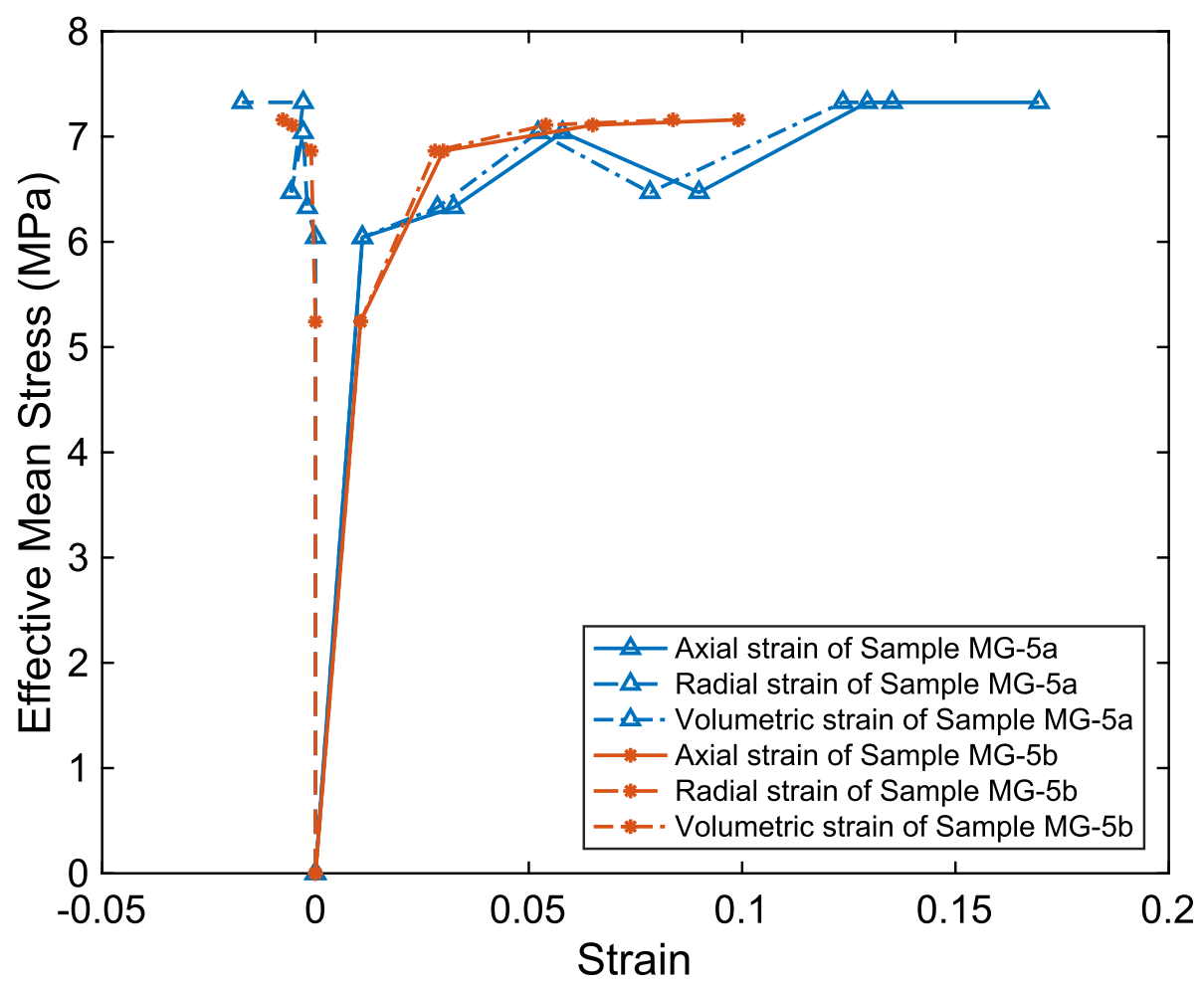

Fig. 4 Effective mean stress (MPa) versus axial strain, radial strain, and volumetric strain of sample MG-5a and sample MG-5b, respectively 
Figure 5 shows the porosity profile along the sample from the top $(0 \mathrm{~mm})$ to the bottom (approx. $26 \mathrm{~mm}$ ) of sample MG-5a and sample MG-5b. A strong heterogeneity of the porosity can be observed in both samples, ranging from 43 to $58 \%$ in sample MG-5a and 38 to $59 \%$ in sample MG-5b. In the first scan (scan 1), both samples are undeformed, and therefore, the porosity profile along the sample has an average porosity of $50 \%$ (Fig. 5). Significantly larger porosity in both samples MG-5a and
MG-5b, with local porosity values up to approximately $60 \%$ is seen at different locations near the middle of the sample.

At $1 \%$ axial strain (scan 2), deformation occurs around the top and bottom boundaries where porosity is slightly reduced (Fig. 5). At 3\% axial strain (scan 3), the porosity of the top and bottom of the sample significantly reduces from 53 to 33\%. Compared to Fig. 3, the stressstrain curve of sample MG-5a shows a relatively larger

(a)

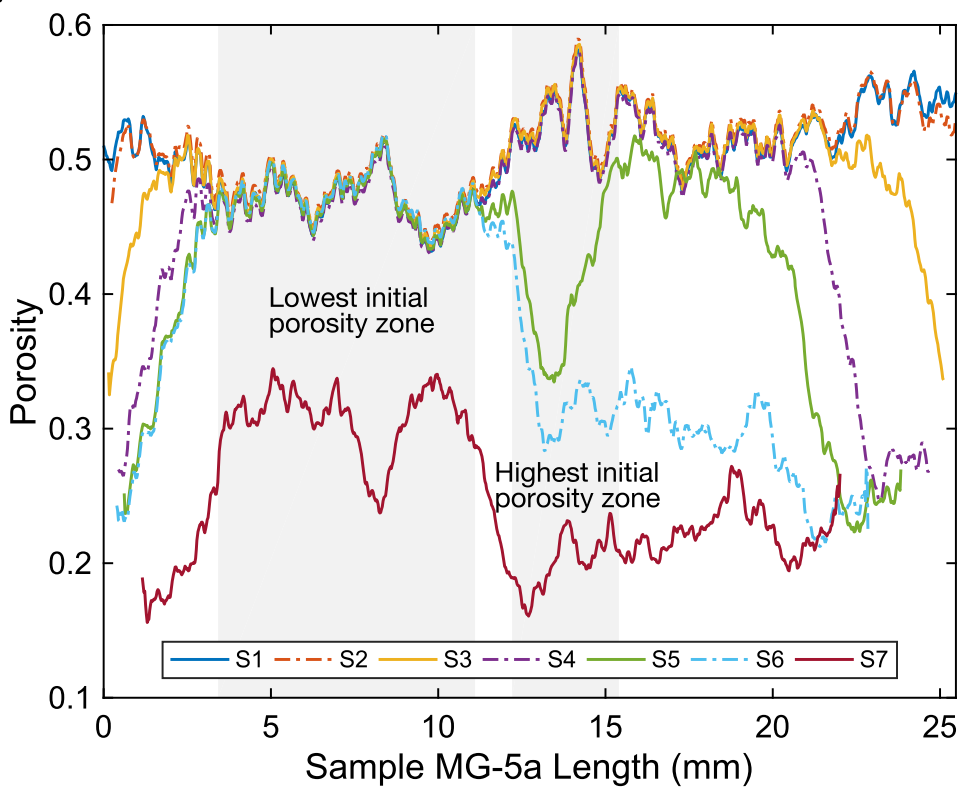

(b)

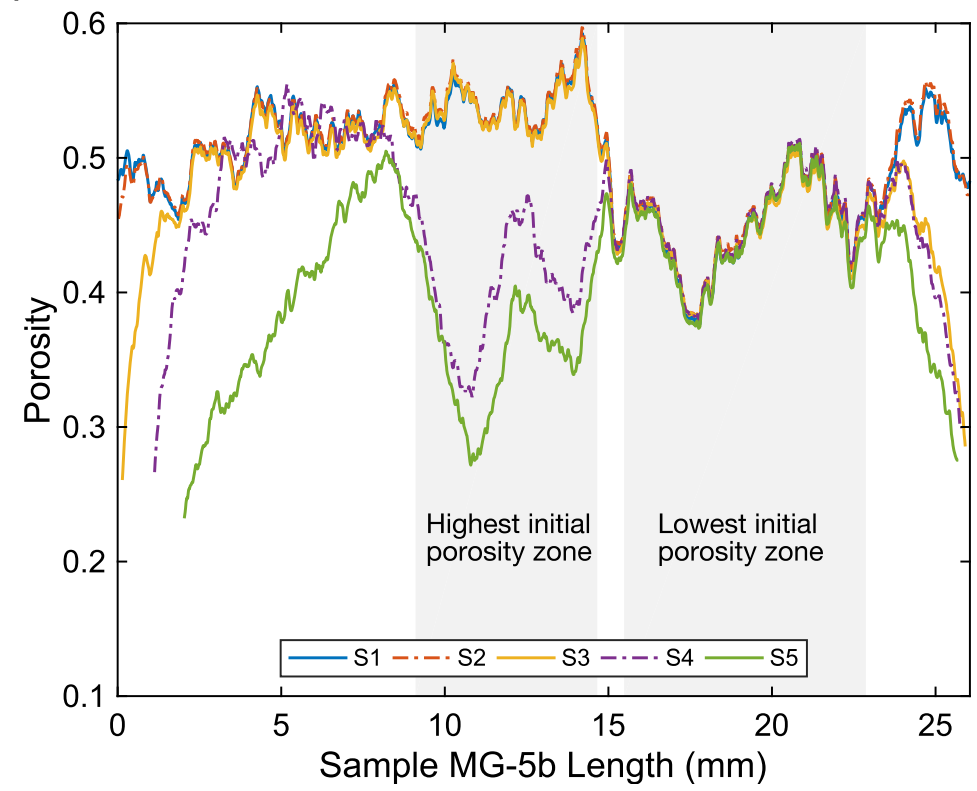

Fig. 5 Porosity profile along the $z$-direction of the specimen extracted from images. a Sample MG-5a and $\mathbf{b}$ sample MG-5b. The zones of lowest initial porosity are used as reference points for the registration 
drop before scan 3 and sample MG-5b shows yielding and slight stress fluctuation before scan 3 followed by two large stress drops between S3 and S4. Comparing with Fig. 3, we observe that the first compaction band corresponds to the yielding or first drop of the axial stress in the stress-strain response. The first compaction bands hence form on top and bottom boundaries of the sample. From scan 3 to scan 4, the axial stress of sample MG-5a increases without any further drop (Fig. 3), while the reduced porosity zones grow towards the middle of the sample and the top and bottom boundary porosity reduces to $28 \%$. However, the axial stress of sample MG-5b shows two large stress drops corresponding to two drops in the porosity profile. These are initiated at the zone of highest local porosity, indicating that the mechanism for compaction band formation is macropore collapse of large porosity zones.

Between scan 4 and scan 5, a large drop in axial stress of sample MG-5a shows similar stress drop of sample MG-5b which occurred between scan 3 and scan 4, the porosity profile of sample MG-5a also shows a significant drop in the middle of the sample having the highest initial porosity of $58 \%$, i.e., where the porosity reduces from 58 to $35 \%$ and a $3 \mathrm{~mm}$ thickness compaction band is formed.

An interesting observation can be made between scans 4 and 5 in Fig. $5 \mathrm{~b}$ showing that in the sample MG$5 \mathrm{~b}$, the region of highest porosity continues to collapse although the local porosity reaches lower values than the bottom of the sample between $15.5 \mathrm{~mm}$ and $22.8 \mathrm{~mm}$. We attribute this to the loss of coherency in the crushed zone. The remainder of the sample still bears structural integrity and can support the applied load. A similar observation can be made for scan 5 to scan 6 in sample MG-5a (Fig. 5a), where the axial stress increases gradually (Fig. 3) and the region from 15.4 to $20.7 \mathrm{~mm}$ of the sample loses structural coherence while the top of the sample from 3.4 to $11.1 \mathrm{~mm}$ remains comparatively intact. Note that the gradual increase in axial stress corresponds to a diffuse growth of compaction in this section. A sudden collapse of the entire sample is observed in scan 7 of sample MG-5a through a dramatic decrease in the porosity throughout the entire sample where porosity reduces to an average of $20 \%$ and the majority of macropores have collapsed. At this stage, the load-bearing framework of the entire sample is lost and the macroscale behavior transition into that of a granular fluid which is not the subject of this paper.

\section{Microscopic view of localization and propagation of compaction bands}

As previously mentioned, an open-source 2D digital image correlation (DIC) code: Ncorr (Blaber et al.
2015) was used to analyze the localization and propagation of compaction bands. Figures 6 and 7 present the strain along $z$-direction on $\mathrm{XZ}$ and $\mathrm{YZ}$ planes, i.e., representative tomograph slices are shown at right angles to each other. As the mechanical load is monotonic and compression sign is positive, only the compressive strain is developed in the sample along $z$-axis on both $\mathrm{XZ}$ and $\mathrm{YZ}$ planes.

No shear or compressive strain localization appears at $1 \%$ axial strain for both specimens (Figs. 6 and 7). However, strain localization is seen for all other scans immediately following the yield point, illustrating that the yield phenomenon is promoted by localized pore collapse. The localization appears at the top and bottom of the specimen and then migrates towards the middle. The nucleation of compaction on the bottom and top platens needs to be treated with caution as this is affected by the interaction of the sample with the platens. With respect to the shear strain profile in Figs. 6b and 7b, only a small boundary effect is noted. Overall shear strains are negligible compared to compressive strain suggesting that the observations are true compaction bands.

When focusing on sample MG-5a, the porosity profile (Fig. 5a) supports the DIC observations where porosity across the sample starts changing considerably after yield. When progressing towards larger strains (17\%), the sample porosity drops to $24.8 \%$, where DIC results show significant complex failure patterns at this stage. The DIC analysis for such high strain regions breaks down as it resolves only the large-scale pore structure. When the structure collapses, an error is reported and the areas are marked by showing the background tomographic images. These zones define regions of strain larger or smaller than the scale bar due to errors in the DIC measurements caused by the local collapse of reference points.

Using the stress-strain curve from Fig. 3 with the porosity profile in Fig. 5a, we infer that each drop in the stress profile after yielding is likely to correspond to the nucleation of a new compaction band while the strain hardening between stress drops represents the growth of the already existing compaction bands. A similar conclusion is also reported by Baud et al. (2004) inferred from experimental observations and Das et al. (2013) through numerical analysis. The stress drop is therefore chosen as an indicator of compaction localization.

A series of $2 \mathrm{D}$ tomography slices superposed with porosity profile on the YZ plane showing the structural changes inside and outside the compaction bands are presented in Fig. 8 i.e. scan 3 to scan 7 of sample MG-5a and scan 1 to scan 5 of sample MG$5 \mathrm{~b}$ were shown. In order to facilitate the correlation 


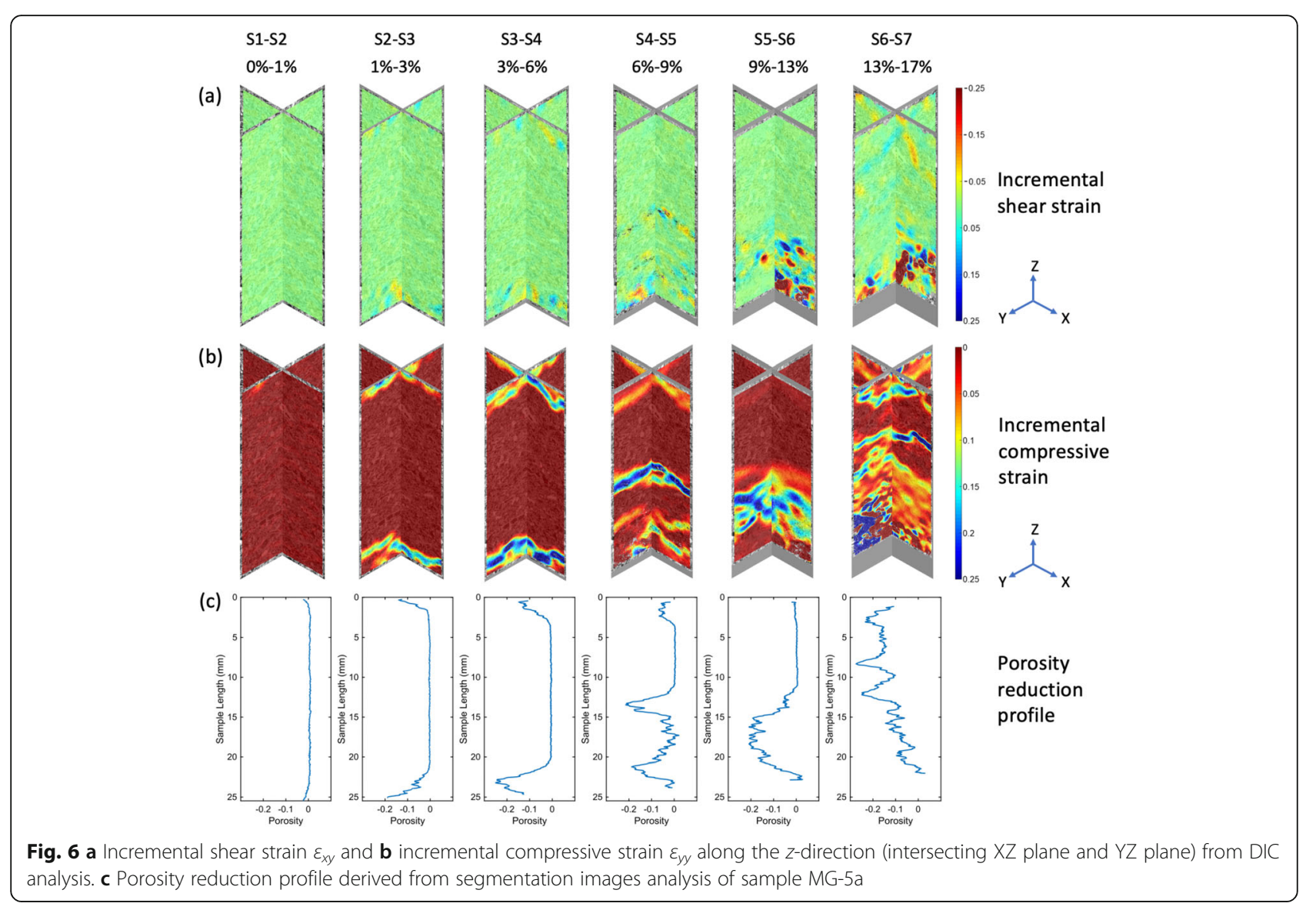

of the images, the arbitrary kinematic reference system was chosen to be the undeformed section of the sample. Scan 3 to scan 7 of sample MG-5a and scan 1 to scan 5 of sample MG-5b were shown here. The red boxes indicate the compaction zones. Almost all of the collapsed pores are located in the compaction band area, and there is no observable collapse outside of the compaction zone. This is additionally supported by the porosity profile (Fig. 5) and strain map (Figs. 6 and 7). The growth of the existing compaction bands leads to a reduction in porosity also seen from the porosity profile (Fig. 5).

A compaction band can be described as discrete or diffuse. A "discrete band" is defined as a few grains thick tabular structure with cumulative strain accommodated by the initiation of additional discrete bands (Wong et al. 2001; Baud et al. 2004). A "diffuse band" is much thicker and accommodates the cumulative strain by lateral propagation of damage (Holcomb and Olsson 2003). Figure 8a shows a single discrete compaction band developed in the middle of the sample MG-5a between scan 4 and scan 5 and few diffuse compacting features in the lower part of the specimen picked up by the DIC analysis (Fig. 7). The discrete compaction band forming in this stage can be compared to experiments on notched sandstone specimens. However, the single discrete compaction band has a thickness of approximately $1180 \mu \mathrm{m}$ compared to the large pore size $60 \sim 80 \mu \mathrm{m}$ which is thicker than the sandstone where a thickness of 2 or 3 times sand grain diameter was reported (Vajdova and Wong 2003; Tembe et al. 2006). Note that in the tomograph shown in Fig. 8a, this observation is not clear and we assume that the diffuse compaction zones picked up by the DIC may not propagate through the entire sample at this early stage. A similar observation, where both discrete and diffuse compaction bands coexist in Berea sandstone was previously reported by Baud et al. (2004).

A representative image of the collapsing macropores obtained from the micro-CT images is shown in Fig. 9 in two selected windows: (a) 310 voxels $\times 232$ voxels and $3.90 \mathrm{~mm} \times 2.92 \mathrm{~mm}$, and (b) 300 voxels $\times 193$ voxels and $3.77 \mathrm{~mm} \times 2.43 \mathrm{~mm}$ from XY plane of sample MG-5b at scan 3 (left) and scan 4 (right). Figure 9a shows large pores which are undeformed at scan 3 , when increasing the axial strain from 3 to $6 \%$, the zone suffered significant deformation and the structure of the fossil shell was 


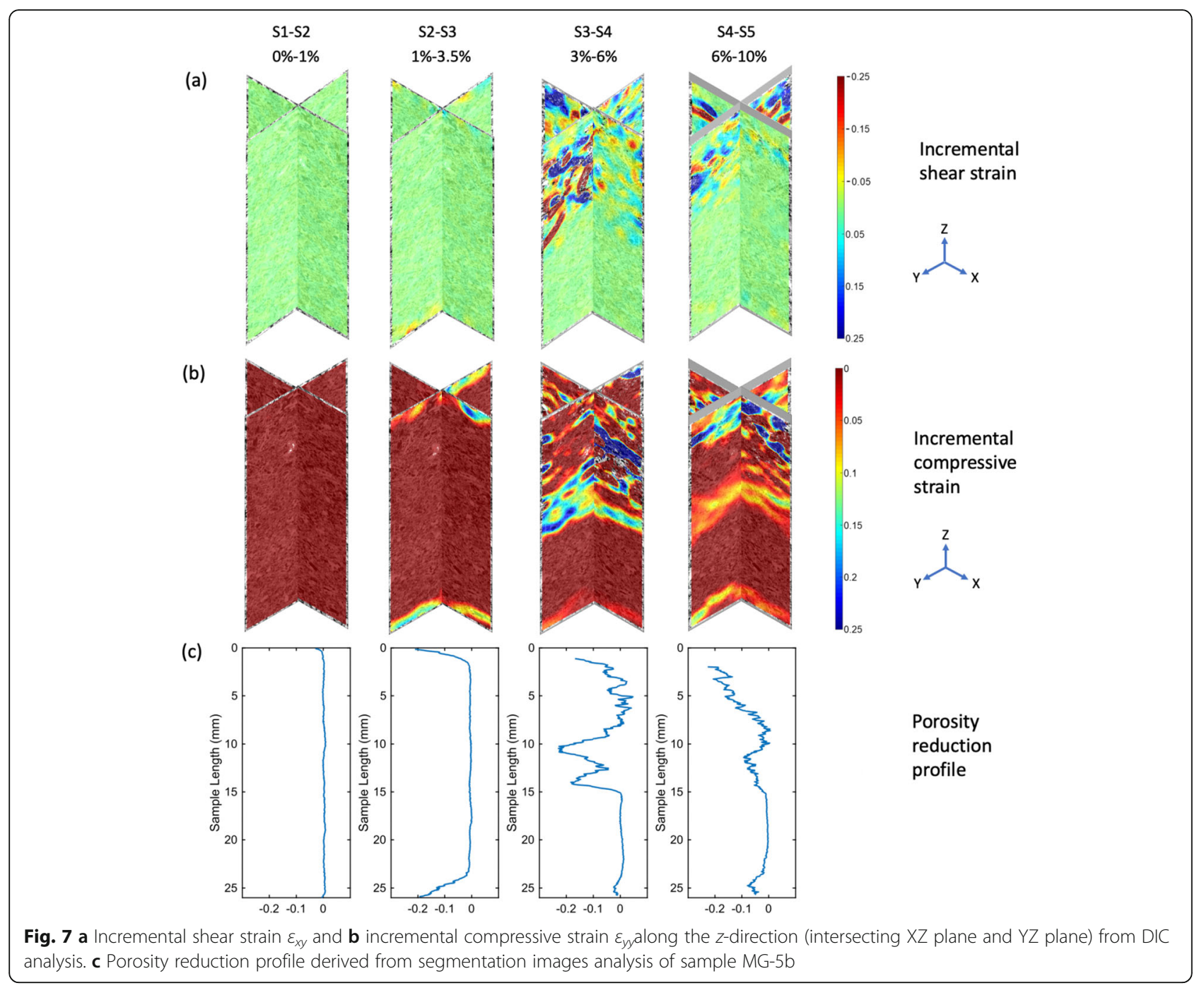

broken into fragments while surrounding grains were crushed into powder and pushed into the macropores at scan 4. Figure 9b shows that some mesopores which have stronger structure still retain their mechanical integrity. Thus, macropore collapse leads to a reduction of the pore throats and acts as a flow barrier.

\section{Discussion}

We have shown that the dynamic micro-CT analyses can provide direct insights into the mechanism of formation and growth of compaction bands with special emphasis on quantifying the role of heterogeneity to trigger the initiation and evolution of compaction bands. Digital rock techniques such as micro-CT images and digital image analysis (DIC) can therefore provide insight into deformation and its localisation in porous rocks. Our main findings are summarized below.

\section{Effect of heterogeneity of local porosity on nucleation and growth}

The nucleation of compaction bands in such a high heterogeneous carbonate rock is still an open question. Previous studies showed the initiation and propagation of compaction bands depend on grain crushing, pore collapse, and breakage of the cementation (Vajdova and Wong 2003; Charalampidou et al. 2011; Das et al. 2011; Han et al. 2013). Previous laboratory experimental studies (Olsson 2001; Baud et al. 2004) observed that the nucleation of compaction bands from the top and bottom boundaries which can be explained as the stiffness mismatch between the sample and the testing device. This causes a local stress heterogeneity on the platens triggering the formation of the first compaction band. Fortin (2006) also pointed out that the material heterogeneities (e.g., high local porosity cluster) can collapse first 

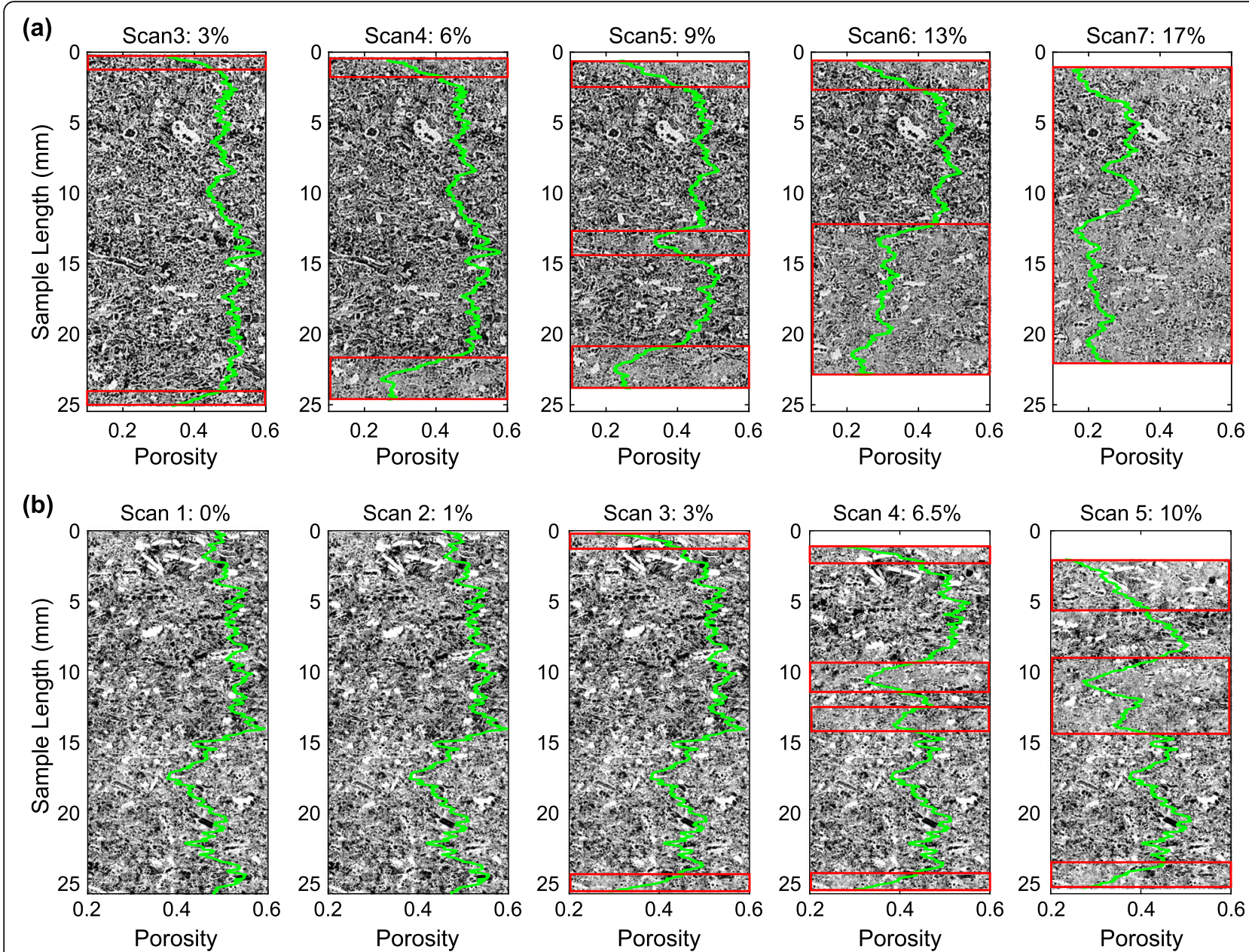

Fig. 8 2D slices of X-ray tomographs of scan 3 to scan 7 on $Y Z$ plane shown on the porosity profile of each scan of $\mathbf{a}$ sample MG-5a and $\mathbf{b}$ sample-5b, respectively, black color represents pores and white color represents grains. Red boxes indicate compaction zones. Note scan 7 of sample MG-5a shows some residual large-scale porosity at the top of the sample (compare with Fig. 5a)

and trigger compaction bands in Bleurswiller sandstone. Numerical breakage mechanics simulations studies also showed that the boundary stiffness mismatch and weak points in a relative homogeneous sample can trigger compaction bands (Das et al. 2013; Das and Buscarnera 2014).

We have confirmed insights on the role of local porosity variation for the nucleation of compaction bands reported in dynamic CT analyses of a lower porosity (26\%) limestone (Huang et al. 2019) which has local porosity heterogeneity near the top of the sample. Their sample was much smaller $(5 \mathrm{~mm}$ diameter and $10 \mathrm{~mm}$ in height) and local heterogeneities therefore played a more significant role. In particular, the effect of the top and bottom platen is more prominent for smaller geometries. We conclude that the propagation of localized compaction bands initiated from both ends of the sample first can be considered a boundary effect attributed to the aforementioned stiffness contrast of sample and testing machine. We have, however, clearly shown that the region of highest porosity in the sample is the nucleation site of the first major compaction band in two repeated experiments (Cilona et al. 2014). This together with the previous work provides strong evidence for the role of local microstructural heterogeneity controlling this mechanical instability. However, we have also shown that the stochastic heterogeneity control reverts back to a continuum formulation as further compaction grows from this initial seed. This results in a diffuse growth of the compaction band from the initial seed.

\section{Link between diffuse and discrete compaction bands}

We were able to show that the new triaxial cell in conjunction with in situ X-ray CT imaging analysis 


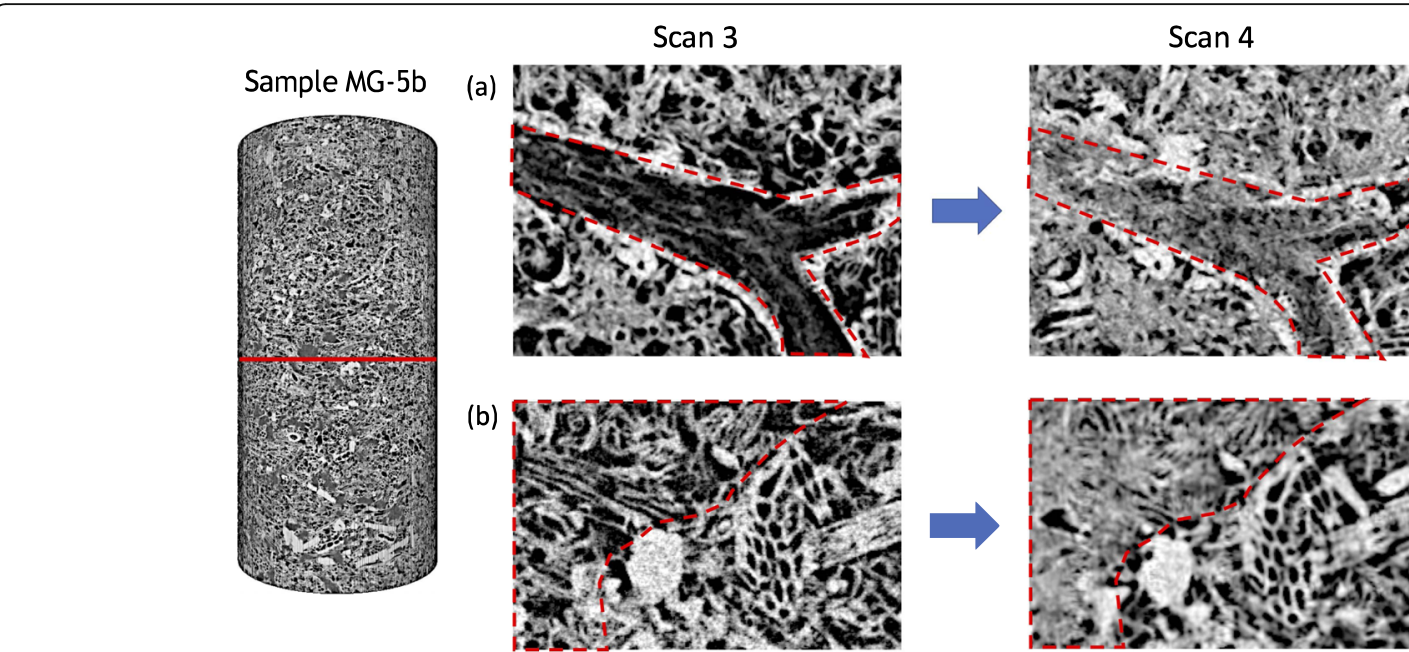

Fig. 9 Two selected 2D tomography image windows a 310 voxels $\times 230$ voxels and $3.90 \mathrm{~mm} \times 2.92 \mathrm{~mm}$, and b 300 voxels $\times 193$ voxels and $3.77 \mathrm{~mm} \times 2.43 \mathrm{~mm}$ from XY plane of sample MG-5b at scan 3 and scan 4 shows the collapse of macropores. The figure on the left shows the $3 \mathrm{D}$ volume rendering of the tomography image and the red line indicates the layer of the chosen window. The weaker structure of the fossil shells which is shown by the dashed boxes is broken into several angular fragments and crushed calcite powder filled the pore space

can directly quantify the location and thickness of the compaction bands during deformation, i.e., within the method resolution, confirming the results of the thin section method. We noted a transition from discrete to diffuse compaction band formation mechanism after the discrete band developed in scan 4 (sample MG-5a). This is similar to observations in some sandstones, for instance, where a combination of diffuse compaction zones as well as discrete compaction bands was found (e.g., Baud et al. (2004)). While the findings from sandstone seem to also apply to the extreme end-member carbonate, the analysis suggests that the switchover from one mode to the other can happen at any particular moment in the experiment. We suggest that a phenomenological observation for discrete compaction bands is a signature large stress drop (Figs. 3a, 5a, and 6b, scans $4-5$; Figs. $3 \mathrm{~b}, 5 \mathrm{~b}$, and $7 \mathrm{~b}$, scans $3-4$ ) while the growth of continuous bands are supported by minor drops followed by strain hardening. This can be seen when comparing Fig. 3a with the Fig. 5a (scans 5-6) without large stress drops. Similar results have been observed by Klein et al. (2001) and Baud et al. (2004) who showed that discrete bands are associated with overall strain hardening punctuated by episodic stress drops. The magnitude of the stress drops has been reported to be related to the ratio between the thickness of the bands and the length of the sample. Small bands in large samples are not inferred to produce noticeable stress drops (e.g., Baud et al. (2004)).

The initial nucleation of discrete compaction bands may be attributed to boundary friction on the top and bottom platen; however, a second more prominent band nucleates in the local region of highest porosity near the center of the sample. Note the different locations of the highest porosity zone in both samples trigger the site of initial localization and subsequent diffusive growth. The discrete bands are argued here to act as the initial seed for a wave-like propagation of discrete micro-compaction bands away from the initial seed. These micro-compaction events are associated with minor stress drops, and we propose that they increase the thickness of the compaction bands in a linear fashion. In order to verify this hypothesis, the technique presented here would need to be carried out in the Synchrotron $\mathrm{X}$-Ray beam to achieve the time resolution required for the detection of the speed of the proposed propagating micro-compaction bands.

The effect of boundary friction on the top and bottom platen is difficult to clearly identify. However, the incremental shear strain on the boundaries (see Figs. $5 \mathrm{~b}$ and $6 \mathrm{~b}$ ) is not affected, and the compaction band that formed near the top and bottom of the sample is abandoned after scan 4 in sample MG-5a and after scan 3 in sample MG-5b (Fig. 5).

\section{Conclusions}

We have presented a comprehensive analysis of the formation of compaction bands in highly porous carbonates using advanced image analysis techniques comprising triaxial testing and analysis, micro-CT tomography, and DIC analysis to perform a 4D analysis of the principal mechanism and their evolution. The techniques were shown to mutually reinforce the main findings offering 
different perspectives of microscopic and macroscopic observations.

Given the comprehensive analyses of the formation of compaction bands that have been performed on sandstones and siliciclastic rocks and the affirmative conclusions of the similarity between earlier studies and the extreme end-member heterogeneous carbonate in this study, as well as the recently published micro-CT work (Huang et al. 2019; Shahin et al. 2019), we may attempt to interpret the phenomenon of compaction band formation using the continuum theories that have been proposed. Issen and Rudnicki (2001) summarized the incipient condition of compaction bands in porous rocks based on a rate-independent constitutive model (Rudnicki and Rice 1975; Rudnicki 1977; Olsson 1999; Issen and Rudnicki 2001). Yield cap failure criteria have been used to determine the onset of instabilities, both in shear and compression (Rudnicki 2004; Grueschow and Rudnicki 2005). Katsman and Aharonov (2006) presented a new damage elastoplastic constitutive model taking into account the formation of the compaction bands under a variety of boundary conditions. Das et al. (2011) proposed a constitutive model based on the concept of grain crushing, which uses a breakage measure as an additional internal variable to the continuum model to track the evolution of grain size distribution. Chemenda and his colleagues $(2011 ; 2012)$ claimed that the onset of compaction bands is triggered by constitutive instabilities resulting from deformation bifurcation rather than anti-crack models of linear elastic fracture mechanics. A recent model emphasized the ratesensitivity of the instability and proposed a new mechanism forming compaction bands and dilation bands (Veveakis and Regenauer-Lieb 2015; Regenauer-Lieb et al. 2016).

All of the abovementioned models fail to explain the observation of growth of diffuse compaction zones as well as the transition from discrete to diffuse compaction band formation reported in our experiments. This calls for an extension of the existing theories to capture the dynamics reported in our experiments. On the flipside, future experimental work needs to adequately address how the strain data can be used for the prediction of failure. This requires innovations for the direct measurement of the behavior of both stress and strain fields at the mesoscale of the localization band.

Triaxial tests show a transitional phase of nucleation of first compaction bands on the top and bottom platens which can be attributed to boundary effects and porosity heterogeneity (Huang et al. 2019). These boundary zones may either progress smoothly into the center of the sample or as in our experiments be aborted and be followed by nucleation of compaction bands on zones of highest porosity. This observation of nucleation of compaction bands on the highest porosity zones shows the strong effect of material heterogeneity to control the site of this mechanical instability also controlling the sites of continued diffusive growth. We therefore conclude that there are two components in the nucleation of compaction bands: (1) the macroscopic boundary conditions (size of the sample), friction on the platen, and its mechanical response as proposed in the incipient continuum mechanics models and (2) the local heterogeneity of the sample (large porosity zones or bedding planes) may become the dominant feature for initial localization (Cilona et al. 2014). This information may also help in identifying reasons for a switch in compaction band formation from discrete to continuous zone growth. Larger porosity values trigger the initial pore collapse followed by a diffuse growth of compaction bands due to loss of mechanical strength inside the collapsed zone. We have also identified in our experiment a second phase transition from macroscopic solid behavior to macroscopic fluid-like behavior when the majority of macropores have collapsed.

\section{Appendix}

Results of the macroscopic triaxial experiment with 30 $\mathrm{mm} \times 60 \mathrm{~mm}$ samples are shown in Fig. A1.

Results of the intensity calibration of sample MG-5b are shown in Figure A2.

Results of the porosity variation of scan 1 and scan 5 of sample MG-5b are shown in Fig. A3.

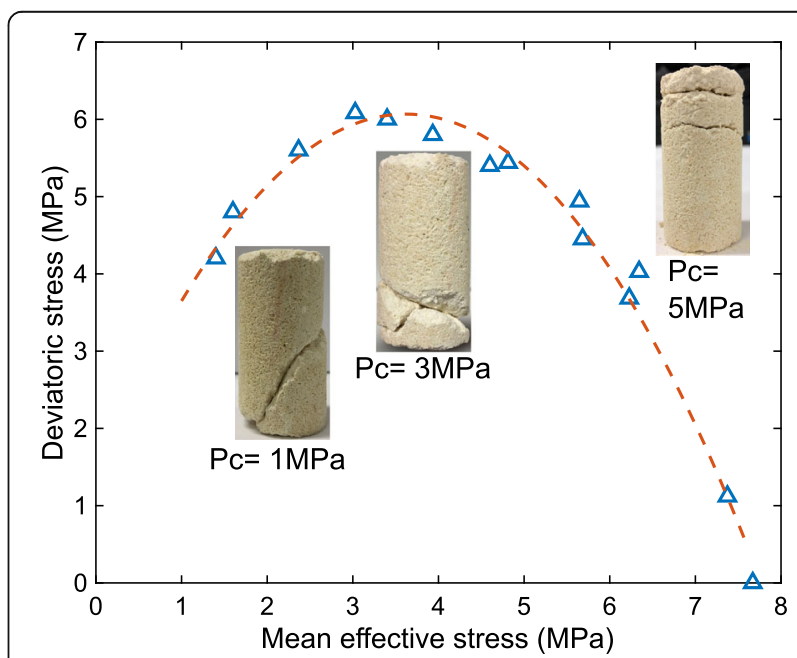

Fig. A1 The yield envelope of carbonate (with a basic quadratic fitting curve). Three exterior failure patterns are observed at $1 \mathrm{MPa}$ (high-angle shear band), $3 \mathrm{MPa}$ (shear-enhanced compaction bands), and $5 \mathrm{MPa}$ (discrete compaction bands) indicating a progressive transition in failure pattern with increasing the confining pressure. 


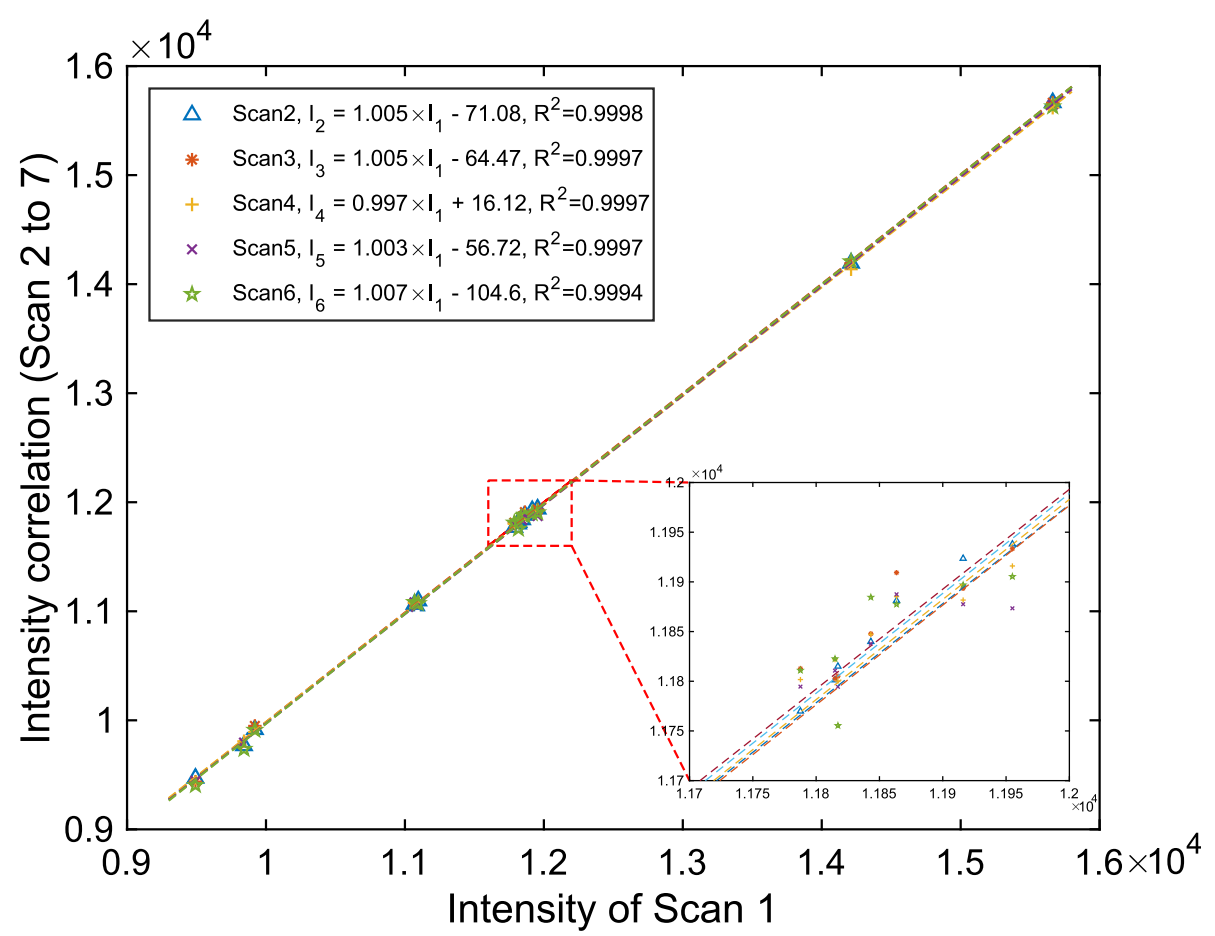

Fig. A2 Intensity calibration for all the scans of sample MG-5a, scans 2 to 6 were calibrated to scan 1. A linear relationship (R2 ranging from 0.9994 to 0.9998) shows perfect consistency for our intensity of each scan.

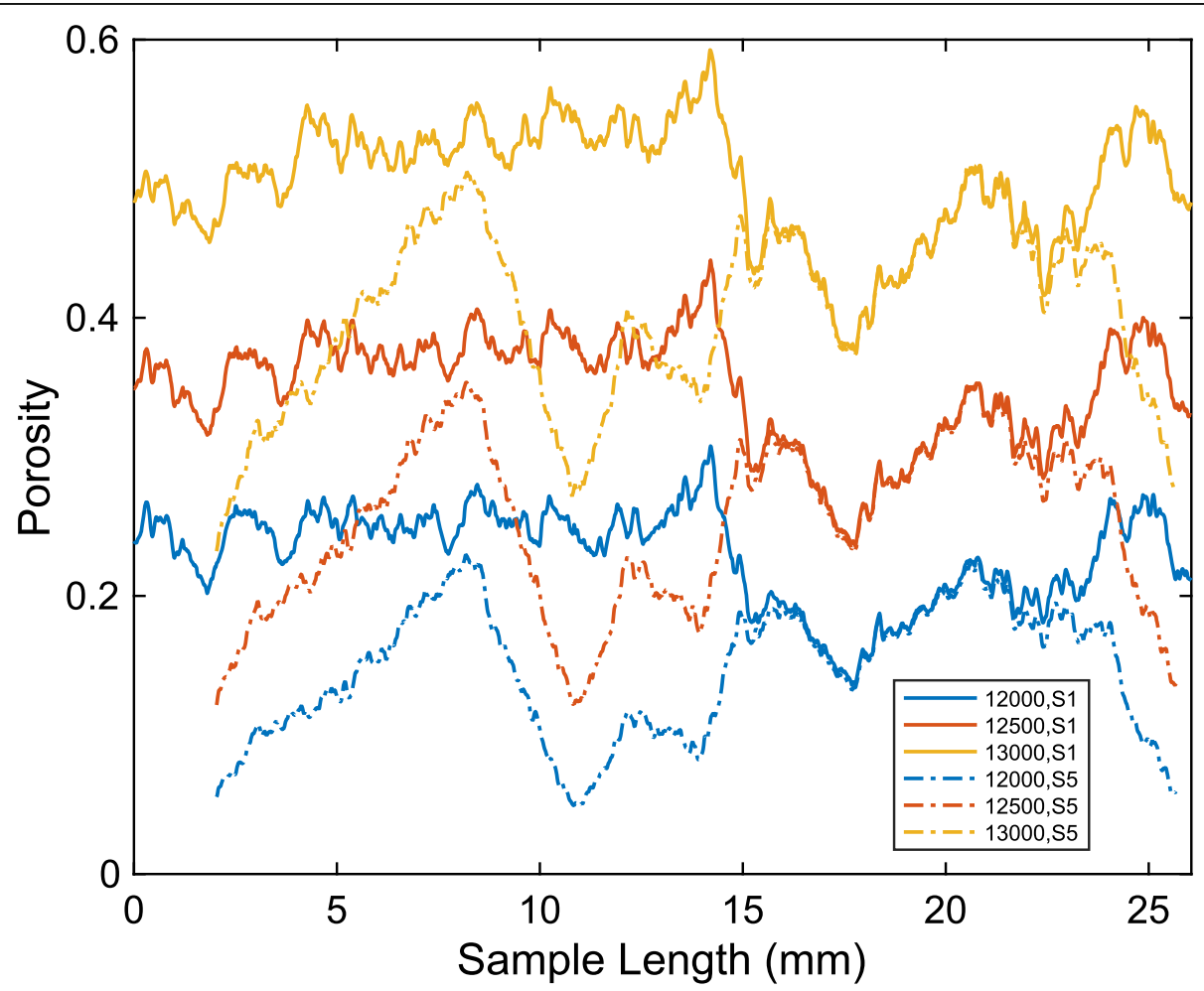

Fig. A3 Porosity profile of sample MG-5b along the $z$-direction of the specimen extracted from segmented images when choosing three different intensities. Solid lines represent scan 1 and dashed lines represent scan 5. Consistency of the trend of the porosity profile can be seen when choosing different intensities. 


\section{Abbreviations}

X-Ray CT: X-ray computer tomography; DIC: Digital image correlation; MICP: Mercury intrusion capillary pressure porosimetry; PEEK: Polyether ether ketone; XRD: X-ray diffraction

\section{Acknowledgements}

We would like to thank the two reviewers of the manuscript for the suggestion to include additional material in the manuscript. We also thank the Tyree X-Ray Laboratory at the School of Mineral and Energy Resources, UNSW, for their assistance in imaging and image reconstruction. The first author would like to acknowledge the fellowship from the UNSW Tuition Fee Scholarship (TFS) and the China Scholarship Council (CSC). In addition to the ARC-Discovery support (ARC Discovery Grants No DP17104550, DP17104557), KRL also acknowledges strategic support from the UNSW through the SPF01 internal funding scheme.

\section{Authors' contributions}

$K R L$ and $H R$ are the project coordinators, proposed the topic, conceived the study, and reviewed the final manuscript. XC conducted the experiments, analyzed the data, and composed the draft of the manuscript. ML helped in the experiment set up and data interpretation. $\mathrm{MH}$ collaborated with the first author in the construction of the manuscript. All authors read and approved the final manuscript.

\section{Funding}

The project was financially supported by the Australian Research Council (ARC Discovery Grants No DP17104550, DP17104557).

\section{Availability of data and materials}

The datasets used and/or analyzed during the current study are available from the corresponding author on reasonable request.

\section{Competing interests}

The authors declare that they have no competing interests.

\section{Author details}

${ }^{1}$ School of Mineral and Energy Resources Engineering, UNSW Sydney, Kensington, Sydney, NSW, Australia. ${ }^{2}$ Department of Civil Engineering, The University of Hong Kong, Hong Kong, China.

Received: 13 March 2020 Accepted: 2 June 2020

\section{Published online: 26 June 2020}

\section{References}

Adamson AW, Gast AP (1967) Physical chemistry of surfaces. vol 15. Interscience New York, New York. https://doi.org/10.1126/science.160.3824.179

Arroyo M, Castellanza R, Nova R (2005) Compaction bands and oedometric testing in cemented soils. Soils Found 45:181-194. https://doi.org/10.3208/ sandf.45.2_181

Arzilli F, Cilona A, Mancini L, Tondi E (2016) Using synchrotron X-ray microtomography to characterize the pore network of reservoir rocks: a case study on carbonates. Adv Water Resour 95:254-263. https://doi.org/10.1016/j. advwatres.2015.07.016

Barraclough TW, Blackford JR, Liebenstein S, Sandfeld S, Stratford TJ, Weinländer G, Zaiser M (2016) Propagating compaction bands in confined compression of snow. Nat Phys 13:272. https://doi.org/10.1038/nphys3966

Bastawros A, Bart-Smith H, Evans A (2000) Experimental analysis of deformation mechanisms in a closed-cell aluminum alloy foam. J Mech Phys Solids 48: 301-322. https://doi.org/10.1016/S0022-5096(99)00035-6

Baud P, Klein E, T-f W (2004) Compaction localization in porous sandstones: spatial evolution of damage and acoustic emission activity. J Struct Geol 26: 603-624. https://doi.org/10.1016/j.jsg.2003.09.002

Baud P, Meredith P, Townend E (2012) Permeability evolution during triaxial compaction of an anisotropic porous sandstone. J Geophys Res Solid Earth 117:B05203. https://doi.org/10.1029/2012JB009176

Baud P, Reuschlé T, Ji Y, Cheung CSN, T-f W (2015) Mechanical compaction and strain localization in Bleurswiller sandstone. J Geophys Res Solid Earth 120: 6501-6522. https://doi.org/10.1002/2015JB012192

Baud P, Schubnel A, Heap M, Rolland A (2017) Inelastic compaction in highporosity limestone monitored using acoustic emissions. J Geophys Res Solid Earth 122:9989-9910,9009. https://doi.org/10.1002/2017JB014627
Baxevanis T, Papamichos E, Flornes O, Larsen I (2006) Compaction bands and induced permeability reduction in Tuffeau de Maastricht calcarenite. Acta Geotech 1:123-135. https://doi.org/10.1007/s11440-006-0011-y

Bedford JD, Faulkner DR, Leclère $H$, Wheeler J (2018) High-resolution mapping of yield curve shape and evolution for porous rock: the effect of inelastic compaction on porous bassanite. J Geophys Res Solid Earth 123:1217-1234. https://doi.org/10.1002/2017JB015250

Blaber J, Adair B, Antoniou A (2015) Ncorr: open-source 2D digital image correlation MATLAB software. Exp Mech 55:1105-1122. https//doi.org/10.1007/s11340-015-0009-1

Bouissou S, Chemenda A, Ambre J, Vacher P, Michel P (2019) Initiation and evolution of a network of deformation bands in a rock analogue material at brittle-ductile transition. Rock Mech Rock Eng 52:737-752. https://doi.org/10. 1007/s00603-018-1641-8

Bourman RP, Murray-Wallace CV, Harvey N (2016) Coastal landscapes of South Australia. University of Adelaide Press, Adelaide. https://doi.org/10.20851/ coast-sa

Charalampidou E-M, Hall SA, Stanchits S, Lewis H, Viggiani G (2011) Characterization of shear and compaction bands in a porous sandstone deformed under triaxial compression. Tectonophysics 503:8-17. https://doi. org/10.1016/j.tecto.2010.09.032

Charalampidou E-M, Hall SA, Stanchits S, Viggiani G, Lewis H (2014) Shearenhanced compaction band identification at the laboratory scale using acoustic and full-field methods. Int J Rock Mech Min Sci 67:240-252. https:// doi.org/10.1016/j.jijmms.2013.05.006

Chemenda Al (2011) Origin of compaction bands: anti-cracking or constitutive instability? Tectonophysics 499:156-164. https://doi.org/10.1016/j.tecto.2011. 01.005

Chemenda Al, Wibberley C, Saillet E (2012) Evolution of compactive shear deformation bands: numerical models and geological data. Tectonophysics 526:56-66. https://doi.org/10.1016/j.tecto.2011.10.003

Chen X, Yu J, Li H, Wang S (2017) Experimental and numerical investigation of permeability evolution with damage of sandstone under triaxial compression. Rock Mech Rock Eng 50:1529-1549. https://doi.org/10.1007/ s00603-017-1169-3

Cheung CS, Baud P, Tf W (2012) Effect of grain size distribution on the development of compaction localization in porous sandstone. Geophys Res Lett 39. https://doi.org/10.1029/2012GL053739

Cilona A et al (2014) The effects of rock heterogeneity on compaction localization in porous carbonates. J Struct Geol 67:75-93. https://doi.org/10 1016/j.jsg.2014.07.008

Das A, Buscarnera G (2014) Simulation of localized compaction in high-porosity calcarenite subjected to boundary constraints. Int J Rock Mech Min Sci 71: 91-104. https://doi.org/10.1016/j.ijrmms.2014.07.004

Das A, Nguyen GD, Einav I (2011) Compaction bands due to grain crushing in porous rocks: a theoretical approach based on breakage mechanics. J Geophys Res Solid Earth 116:B08203. https://doi.org/10.1029/2011JB008265

Das A, Nguyen GD, Einav I (2013) The propagation of compaction bands in porous rocks based on breakage mechanics. J Geophys Res Solid Earth 118 : 2049-2066. https://doi.org/10.1002/jgrb.50193

Deng S, Zuo L, Aydin A, Dvorkin J, Mukerji T (2015) Permeability characterization of natural compaction bands using core flooding experiments and threedimensional image-based analysis: comparing and contrasting the results from two different methods. AAPG Bull 99:27-49. https://doi.org/10.1306/07071413211

Detournay C (2009) Numerical modeling of the slit mode of cavity evolution associated with sand production. SPE J 14:797-804. https://doi.org/10.2118/ 116168-PA

Eichhubl P, Hooker JN, Laubach SE (2010) Pure and shear-enhanced compaction bands in Aztec Sandstone. J Struct Geol 32:1873-1886. https://doi.org/10. 1016/j.jsg.2010.02.004

Fortin J, Schubnel A, Guéguen Y (2005) Elastic wave velocities and permeability evolution during compaction of Bleurswiller sandstone. Int J Rock Mech Min Sci 42:873-889. https://doi.org/10.1016/j.jjrmms.2005.05.002

Fortin J, Stanchits S, Dresen G, Guéguen Y (2006) Acoustic emission and velocities associated with the formation of compaction bands in sandstone. $J$ Geophys Res Solid Earth 111:B10203. https://doi.org/10.1029/2005JB003854

Frangakis AS, Hegerl R (2001) Noise reduction in electron tomographic reconstructions using nonlinear anisotropic diffusion. J Struct Biol 135:239_ 250. https://doi.org/10.1006/jsbi.2001.4406

Gray F, Cen J, Shah S, Crawshaw J, Boek E (2016) Simulating dispersion in porous media and the influence of segmentation on stagnancy in carbonates. Adv Water Resour 97:1-10. https://doi.org/10.1016/j.advwatres.2016.08.009 
Grueschow E, Rudnicki JW (2005) Elliptic yield cap constitutive modeling for high porosity sandstone. Int J Solids Struct 42:4574-4587. https://doi.org/10.1016/j. ijsolstr.2005.02.001

Guillard F, Golshan P, Shen L, Valdes JR, Einav I (2015) Dynamic patterns of compaction in brittle porous media. Nat Phys 11:835. https://doi.org/10.1038/ NPHYS3424

Haimson B (2001) Fracture-like borehole breakouts in high-porosity sandstone: are they caused by compaction bands? Phys Chem Earth A 26:15-20. https:// doi.org/10.1016/S1464-1895(01)00016-3

Haimson B, Kovacich J (2003) Borehole instability in high-porosity Berea sandstone and factors affecting dimensions and shape of fracture-like breakouts. Eng Geol 69:219-231. https://doi.org/10.1016/S00137952(02)00283-1

Hall SA, Bornert M, Desrues J, Pannier Y, Lenoir N, Viggiani G, Bésuelle P (2010) Discrete and continuum analysis of localised deformation in sand using $X$-ray $\mu C T$ and volumetric digital image correlation. Géotechnique 60:315-322

Hall SA, Desrues J, Viggiani G, Bésuelle P, Andò E (2012) Experimental characterisation of (localised) deformation phenomena in granular geomaterials from sample down to inter-and intra-grain scales. Procedia IUTAM 4:54-65. https://doi.org/10.1016/j.piutam.2012.05.007

Han G, Liu X, Wang E (2013) Experimental study on formation mechanism of compaction bands in weathered rocks with high porosity. Sci China Technol Sci 56:2563-2571. https://doi.org/10.1007/s11431-013-5322-2

Hashimoto Y, Stipp M, Lewis JC, Wuttke F (2019) Paleo-stress orientations and magnitudes from triaxial testing and stress inversion analysis in Nankai accretionary prism sediments. Prog in Earth and Planet Sci 6:1-11. https://doi. org/10.1186/2197-4284-1-13

Hill RE (1993) Analysis of deformation bands in the Aztec sandstone, Valley of Fire State Park, Nevada. University of Nevada, MS thesis

Holcomb D, Olsson W (2003) Compaction localization and fluid flow. J Geophys Res Solid Earth 108:2290. https://doi.org/10.1029/2001JB000813

Huang L, Baud P, Cordonnier B, Renard F, Liu L, T-f W (2019) Synchrotron X-ray imaging in 4D: multiscale failure and compaction localization in triaxially compressed porous limestone. Earth Planet Sci Lett 528:115831. https://doi. org/10.1016/j.epsl.2019.115831

Hurley RC, Lind J, Pagan DC, Akin MC, Herbold EB (2018) In situ grain fracture mechanics during uniaxial compaction of granular solids. J Mech Phys Solids 112:273-290. https://doi.org/10.1016/j.jmps.2017.12.007

ISRM (2007) The complete ISRM suggested methods for rock characterization, testing and monitoring: 1974-2006. International Soc for Rock Mechanics, Commission on Testing Methods. https://doi.org/10. 2113/gseegeosci.15.1.47

Issen K, Rudnicki J (2001) Theory of compaction bands in porous rock. Phys Chem Earth A 26:95-100. https://doi.org/10.1016/S1464-1895(01)00031-X

Ji Y, Baud P, Vajdova V, T-f W (2012) Characterization of pore geometry of Indiana limestone in relation to mechanical compaction. Oil Gas Sci Technol - Rev IFP Energies nouvelles 67:753-775. https://doi.org/10.2516/ogst/2012051

Ji Y, Hall SA, Baud P, T-f W (2014) Characterization of pore structure and strain localization in Majella limestone by X-ray computed tomography and digital image correlation. Geophys J Int 200:701-719. https://doi.org/10.1093/gji/ ggu414

Katsman R, Aharonov E (2006) A study of compaction bands originating from cracks, notches, and compacted defects. J Struct Geol 28:508-518. https:// doi.org/10.1016/j.jsg.2005.12.007

Kingston AM, Myers GR, Latham SJ, Li H, Veldkamp JP, Sheppard AP Optimized Xray source scanning trajectories for iterative reconstruction in high coneangle tomography. In: Developments in X-ray tomography X, 2016. International Society for Optics and Photonics, p 996712. https://doi.org/10. $1117 / 12.2238297$

Klein E, Baud P, Reuschlé T, Wong T (2001) Mechanical behaviour and failure mode of Bentheim sandstone under triaxial compression. Phys Chem Earth A 26:21-25. https://doi.org/10.1016/S1464-1895(01)00017-5

Latham S, Varslot T, Sheppard A Image registration: enhancing and calibrating $X$ ray micro-CT imaging. In: Proceedings of the International Symposium of the Society of Core Analysts 2008, Abu Dhabi, UAE, 2008. Society of Core Analysts, pp pp. 1-12.

Lenoir N, Andrade J, Sun W, Rudnicki J (2010) In situ permeability measurements inside compaction bands using X-ray CT and lattice Boltzmann calculations. In: Reed KAAAH (ed) Advances in Computed Tomography for Geomaterials: GeoX2010. John Wiley and Sons, Hoboken, New Jersey, pp 279-286. https:// doi.org/10.1002/9781118557723.ch33
Lenoir N, Bornert M, Desrues J, Bésuelle P, Viggiani G (2007) Volumetric digital image correlation applied to X-ray microtomography images from triaxial compression tests on argillaceous rock. Strain 43:193-205. https:/doi.org/10. 1111/j.1475-1305.2007.00348.x

Li L, Papamichos E, Cerasi P Investigation of sand production mechanisms using DEM with fluid flow. In: Proceedings of the International Symposium of the International Society for Rock Mechanics: Eurock 2006, Liège, Belgium, 2006. pp 241-247. https://doi.org/10.1201/9781439833469.ch33

Love A, Herczeg A, Armstrong D, Stadter F, Mazor E (1993) Groundwater flow regime within the Gambier Embayment of the Otway Basin, Australia: evidence from hydraulics and hydrochemistry. J Hydrol 143:297-338. https:// doi.org/10.1016/0022-1694(93)90197-H

Lv A, Masoumi H, Walsh SD, Roshan H (2019) Elastic-Softening-Plasticity Around a Borehole: An Analytical and Experimental Study. Rock Mech Rock Eng 52: 1149-1164. https://doi.org/10.1007/s00603-018-1650-7

McBeck J, Aiken JM, Ben-Zion Y, Renard F (2020) Predicting the proximity to macroscopic failure using local strain populations from dynamic in situ X-ray tomography triaxial compression experiments on rocks. Earth Planet Sci Lett 543:116344 https://doi.org/10.1016/j.epsl.2020.116344

McBeck J, Kobchenko M, Hall SA, Tudisco E, Cordonnier B, Meakin P, Renard F (2018) Investigating the onset of strain localization within anisotropic shale using digital volume correlation of time-resolved X-ray microtomography images. J Geophys Res Solid Earth 123:7509-7528. https://doi.org/10.1029/ 2018jb015676

Nicolas A, Fortin J, Regnet J, Dimanov A, Guéguen Y (2016) Brittle and semibrittle behaviours of a carbonate rock: influence of water and temperature. Geophys J Int 206:438-456. https://doi.org/10.1093/gji/ggw154

Oka F, Kimoto S, Higo Y, Ohta H, Sanagawa T, Kodaka T (2011) An elastoviscoplastic model for diatomaceous mudstone and numerical simulation of compaction bands. Int J Numer Anal Meth Geomech 35:244-263. https://doi. org/10.1002/nag.987

Olsson WA (1999) Theoretical and experimental investigation of compaction bands in porous rock. J Geophys Res Solid Earth 104:7219-7228. https://doi. org/10.1029/1998JB900120

Olsson WA (2001) Quasistatic propagation of compaction fronts in porous rock. Mech Mater 33:659-668. https://doi.org/10.1016/S0167-6636(01)00078-3

Papazoglou A, Shahin G, Marinelli F, Dano C, Buscarnera G, Viggiani G (2017) Localized compaction in tuffeau de maastricht: experiments and modeling. In: International Workshop on Bifurcation and Degradation in Geomaterials, Limassol, Cyprus, 2017. Springer, pp 481-488. https://doi.org/10.1007/978-3319-56397-8_61

Papka SD, Kyriakides S (1998) Experiments and full-scale numerical simulations of in-plane crushing of a honeycomb. Acta Mater 46:2765-2776. https://doi.org/ 10.1016/S1359-6454(97)00453-9

Pirzada MA, Zoorabadi M, Ramandi HL, Canbulat I, Roshan H (2018) CO2 sorption induced damage in coals in unconfined and confined stress states: a micrometer to core scale investigation. Int J Coal Geol 198:167-176. https:// doi.org/10.1016/j.coal.2018.09.009

Rahmati H, Nouri A, Chan D, Vaziri H (2014) Simulation of drilling-induced compaction bands using discrete element method. Int J Numer Anal Meth Geomech 38:37-50. https://doi.org/10.1002/nag.2194

Rashid F, Glover PWJ, Lorinczi P, Hussein D, Lawrence JA (2017) Microstructural controls on reservoir quality in tight oil carbonate reservoir rocks. J Petrol Sci Eng 156:814-826. https://doi.org/10.1016/j.petrol.2017.06.056

Regenauer-Lieb K, Poulet T, Veveakis M (2016) A novel wave-mechanics approach for fluid flow in unconventional resources. Lead Edge 35:90-97. https://doi. org/10.1190/tle35010090.1

Renard F, Bernard D, Desrues J, Ougier-Simonin A (2009) 3D imaging of fracture propagation using synchrotron X-ray microtomography. Earth Planet Sci Lett 286:285-291. https://doi.org/10.1016/j.epsl.2009.06.040

Renard F et al (2019) Dynamic in situ three-dimensional imaging and digital volume correlation analysis to quantify strain localization and fracture coalescence in sandstone. Pure Appl Geophys 176:1083-1115. https://doi. org/10.1007/s00024-018-2003-X

Roshan H, Chen X, Pirzada MA, Regenauer-Lieb K (2019a) Permeability measurements during triaxial and direct shear loading using a novel $X$ ray transparent apparatus: fractured shale examples from Beetaloo basin, Australia. NDT\&E Int 107:102129. https://doi.org/10.1016/j.ndteint.2019. 102129

Roshan H, Lv A, Xu Y, Masoumi H, Regenauer-Lieb K (2019b) New generation of hoek cells. Geotech Test J 42:747-760. https://doi.org/10.1520/GTJ20170110 
Roshan $\mathrm{H}$ et al (2016) Total porosity of tight rocks: a welcome to the heat transfer technique. Energy Fuel 30:10072-10079. https://doi.org/10.1021/acs. energyfuels.6b01339

Rudnicki JW (1977) The inception of faulting in a rock mass with a weakened zone. J Geophys Res 82:844-854. https://doi.org/10.1029/JB082i005p00844

Rudnicki JW (2004) Shear and compaction band formation on an elliptic yield cap. J Geophys Res Solid Earth 109:B03402. https://doi.org/10.1029/ 2003JB002633

Rudnicki JW, Rice J (1975) Conditions for the localization of deformation in pressure-sensitive dilatant materials. J Mech Phys Solids 23:371-394. https:// doi.org/10.1016/0022-5096(75)90001-0

Rustichelli A, Tondi E, Agosta F, Cilona A, Giorgioni M (2012) Development and distribution of bed-parallel compaction bands and pressure solution seams in carbonates (Bolognano Formation, Majella Mountain, Italy). J Struct Geol 37:181-199. https://doi.org/10.1016/j.jsg.2012.01.007

Shahin G, Papazoglou A, Marinelli F, Buscarnera G (2019) Simulation of localized compaction in Tuffeau de Maastricht based on evidence from X-ray tomography. Int J Rock Mech Min Sci 121:104039. https://doi.org/10.1016/j. ijrmms.2019.05.005

Sheppard A et al (2014) Techniques in helical scanning, dynamic imaging and image segmentation for improved quantitative analysis with $\mathrm{X}$-ray micro-CT. Nuclear Instruments and Methods in Physics Research Section B: Beam Interactions with Materials and Atoms 324:49-56. https://doi.org/10.1016/j. nimb.2013.08.072

Sheppard AP, Sok RM, Averdunk H (2004) Techniques for image enhancement and segmentation of tomographic images of porous materials. Physica A Stat Mech Appl 339:145-151. https://doi.org/10.1016/j.physa.2004.03.057

Sternlof KR, Karimi-Fard M, Pollard DD, Durlofsky L (2006) Flow and transport effects of compaction bands in sandstone at scales relevant to aquifer and reservoir management. Water Resources Research 42 https://doi.org/10.1029/ 2005WR004664

Sternlof KR, Rudnicki JW, Pollard DD (2005) Anticrack inclusion model for compaction bands in sandstone. J Geophys Res Solid Earth 110:B11403. https://doi.org/10.1029/2005JB003764

Sun W, Andrade JE, Rudnicki JW, Eichhubl P (2011) Connecting microstructural attributes and permeability from 3D tomographic images of in situ shearenhanced compaction bands using multiscale computations. Geophys Res Lett 38 https://doi.org/10.1029/2011GL047683

Takano D, Lenoir N, Otani J, Hall SA (2015) Localised deformation in a widegrained sand under triaxial compression revealed by X-ray tomography and digital image correlation. Soils Found 55:906-915. https://doi.org/10.1016/j. sandf.2015.06.020

Tembe S, Baud P, Wong Tf (2008) Stress conditions for the propagation of discrete compaction bands in porous sandstone. J Geophys Res Solid Earth 113:B09409. https://doi.org/10.1029/2007JB005439

Tembe S, Vajdova V, Wong Tf, Zhu W (2006) Initiation and propagation of strain localization in circumferentially notched samples of two porous sandstones. J Geophys Res Solid Earth 111:B02409. https://doi.org/10.1029/2005JB003611

Wong T-f, Baud P, Klein E (2001) Localized failure modes in a compactant porous rock. Geophys Res Lett 28:2521-2524. https://doi.org/10.1029/2001GL012960.

Tondi E, Antonellini M, Aydin A, Marchegiani L, Cello G (2006) The role of deformation bands, stylolites and sheared stylolites in fault development in carbonate grainstones of Majella Mountain, Italy. J Struct Geol 28:376-391. https://doi.org/10.1016/j.jsg.2005.12.001

Townend E, Thompson BD, Benson PM, Meredith PG, Baud P, Young RP (2008) Imaging compaction band propagation in Diemelstadt sandstone using acoustic emission locations. Geophys Res Lett 35 https://doi.org/10.1029/ 2008GL034723

Tudisco E, Hall SA, Charalampidou EM, Kardjilov N, Hilger A, Sone H (2015) Fullfield measurements of strain localisation in sandstone by neutron tomography and 3D-volumetric digital image correlation. Phys Procedia 69 509-515. https://doi.org/10.1016/j.phpro.2015.07.072

Vajdova V, Baud P, Wong Tf (2004) Permeability evolution during localized deformation in Bentheim sandstone. J Geophys Res Solid Earth 109:B10406. https://doi.org/10.1029/2003JB002942

Vajdova V, Wong TF (2003) Incremental propagation of discrete compaction bands: acoustic emission and microstructural observations on circumferentially notched samples of Bentheim. Geophys Res Lett 30 https:// doi.org/10.1029/2003GL017750

Varslot T, Kingston A, Sheppard A, Sakellariou A Fast high-resolution micro-CT with exact reconstruction methods. In: the SPIE - Progress in Biomedical
Optics and Imaging, San Diego, California, United States, 2010. International Society for Optics and Photonics, p 780413. https://doi.org/10.1117/12. 860298

Veveakis E, Regenauer-Lieb K (2015) Cnoidal waves in solids. J Mech Phys Solids 78:231-248. https://doi.org/10.1016/j.jmps.2015.02.010

Viggiani G, Hall SA Full-field measurements, a new tool for laboratory experimental geomechanics. In: Fourth symposium on deformation characteristics of geomaterials, 2008. IOS Press Amsterdam, pp 3-26.

Viggiani G, Lenoir N, Bésuelle P, Di Michiel M, Marello S, Desrues J, Kretzschmer M (2004) X-ray microtomography for studying localized deformation in finegrained geomaterials under triaxial compression. C R Mecanique 332:819-826. https://doi.org/10.1016/j.crme.2004.05.006

Viggiani $\mathrm{G}$, Tengattini A Recent developments in laboratory testing of geomaterials with emphasis on imaging. In: Proceedings of the XVII ECSMGE2019 Reykjavík, Iceland, 2019/9 2019.

Washburn EW (1921) Note on a method of determining the distribution of pore sizes in a porous material. Proc Natl Acad Sci U S A 7:115. https://doi.org/10. 1073/pnas.7.4.115

Wong T-f, Baud P (2012) The brittle-ductile transition in porous rock: a review. J Struct Geol 44:25-53. https://doi.org/10.1016/j.jsg.2012.07.010

\section{Publisher's Note}

Springer Nature remains neutral with regard to jurisdictional claims in published maps and institutional affiliations.

\section{Submit your manuscript to a SpringerOpen ${ }^{\circ}$ journal and benefit from:}

- Convenient online submission

- Rigorous peer review

- Open access: articles freely available online

- High visibility within the field

- Retaining the copyright to your article

Submit your next manuscript at $\boldsymbol{\nabla}$ springeropen.com 